دراسة لمحددات إستجابة الزراع لإستخدام المرشدين الزراعيين للطرق الإرشادية بمنطقة الجبل الأخضر بالجماهيرية الليبية الزية الزئية

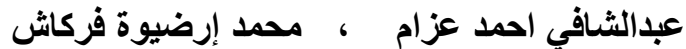 \\ قسم الإرشاد الزراعي والتنمية الريفيةـ كلية الزراعة ـ جامعة عمر المختار- ليبيا
}

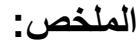

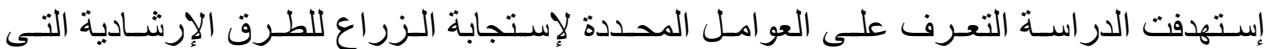

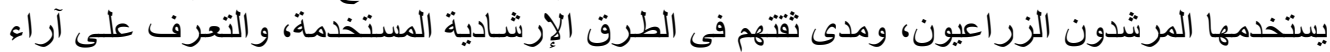

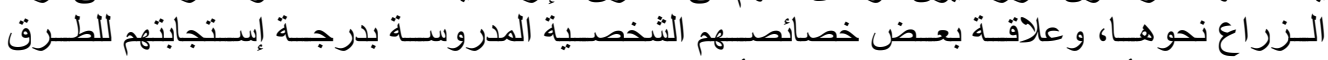

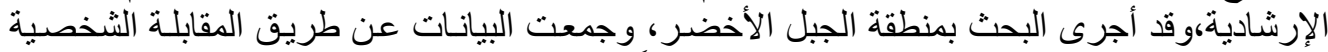

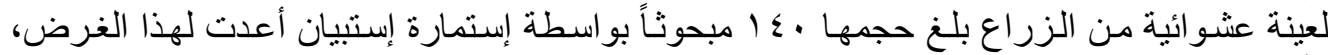

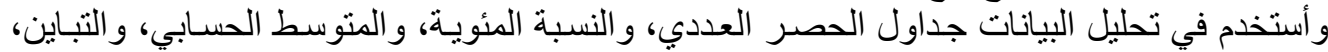

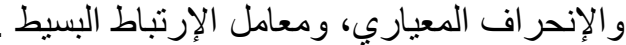

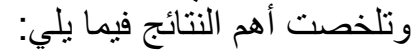

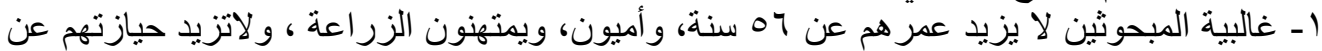

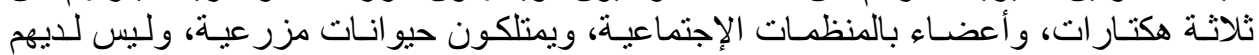
مشرو عات زر اعية.

r- تراوحت نسبة إستجابة المبحوثين للطرق الإرشادية المدروسة بين ع ا.ب٪\% (الخطابات الثخصية)

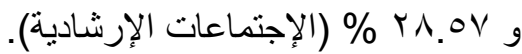

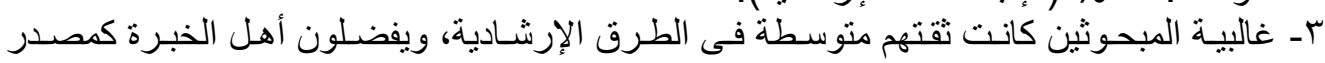

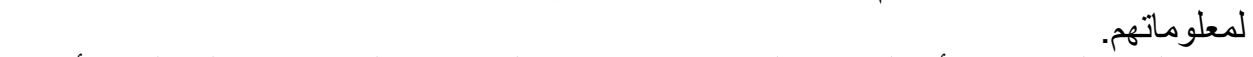

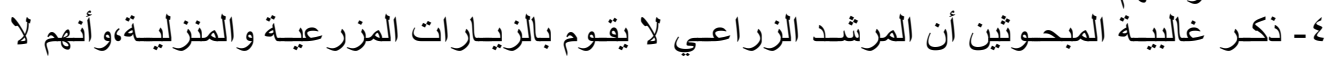
يستفيدون من هذه الطريقة. هـ لم يسبق لغالبيـة المبحوثين حضور الإجتماعـات الإرشـادية وذللك لعدم معرفتهم بموعد ومكان

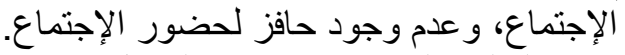

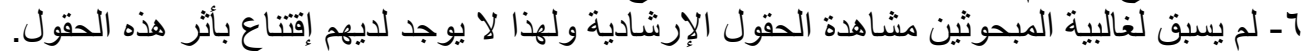

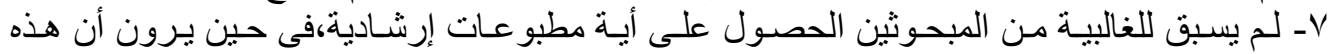

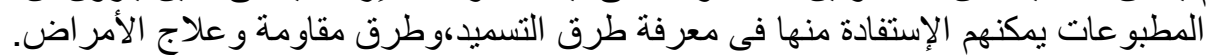

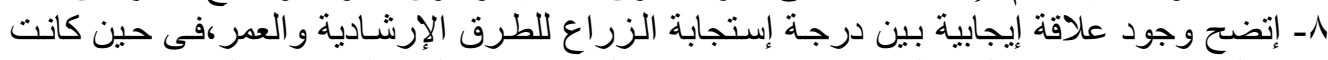

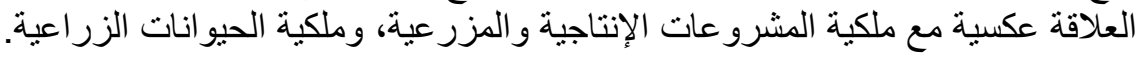

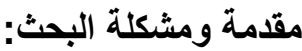

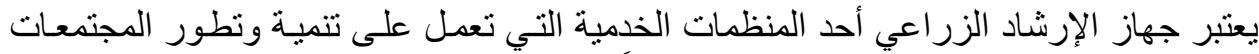

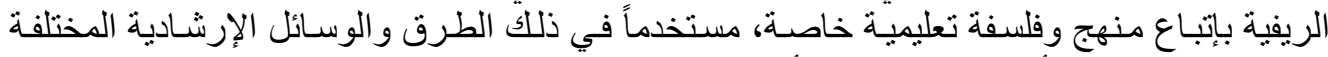

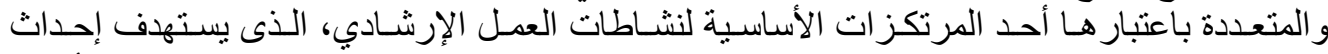

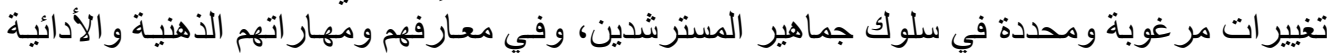

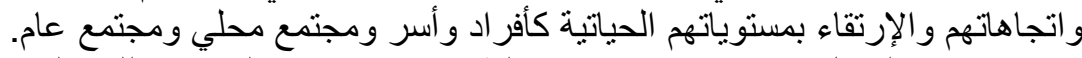

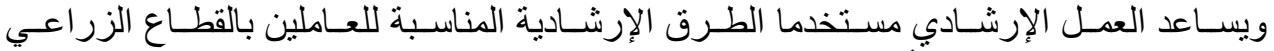

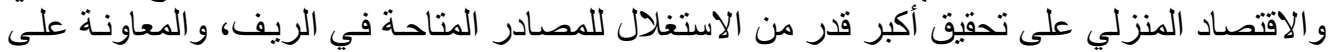

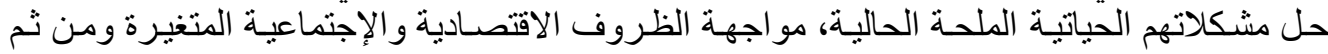

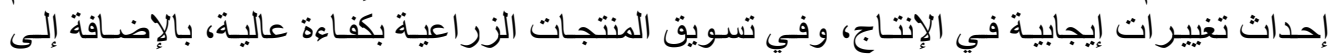

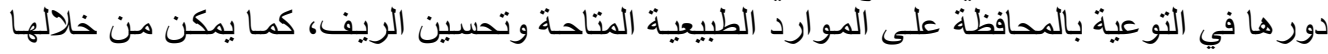

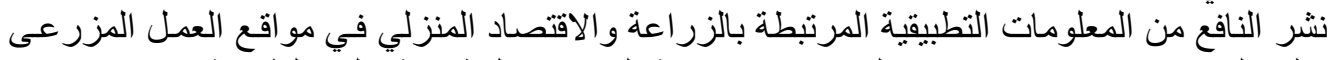

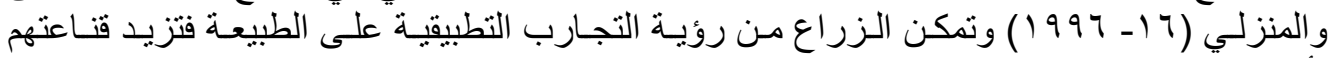
بأهميتها وبنتائجها.

Fayoum J. Agric. Res. \& Dev., Vol.23, No.2, (B) July, 2009 


\section{Iro}

وتساعد الطرق الإرشادية في اعتياد الزراع على الأسلوب المستخدم في هذه الطرق وزيـادة ثقة الزّة

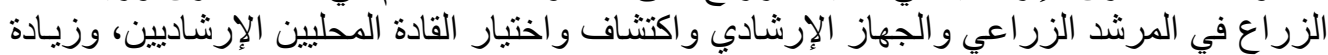

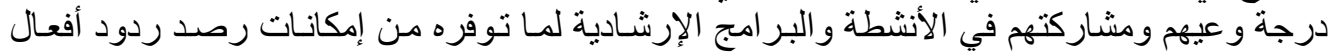

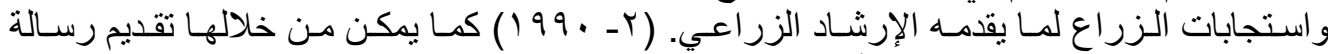
إرشـادية تم إعدادها وتتفيذها وفق أسس تعليميـة تتناسب مـع إمكانيـات ومستويات المستهدفين منها،

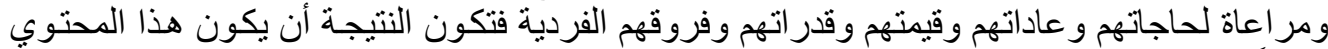

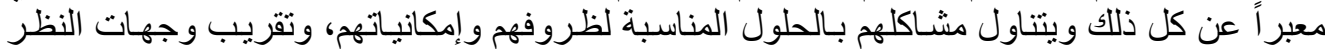
من خلال الفهم المتبادل.

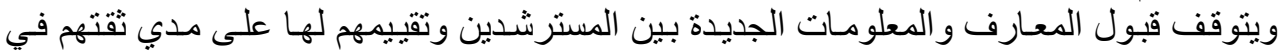
قدر ات ومهار ات مصادر المعلومات، و على النظام الاجتماعي السائد، والأنماط السلوكية، وتجانس كل

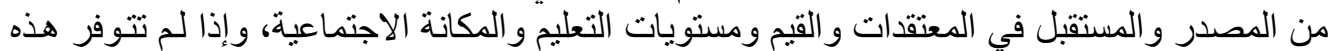

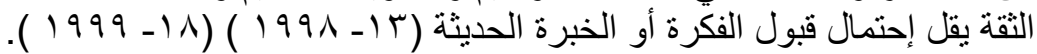

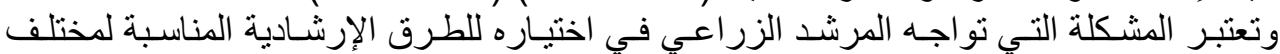

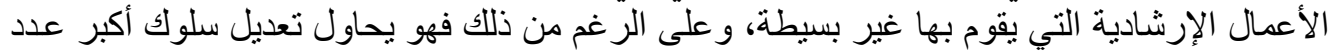

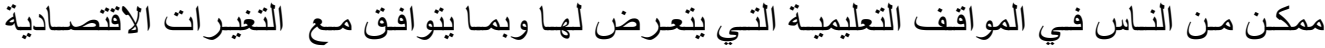

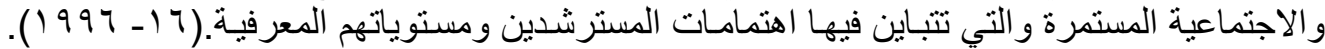

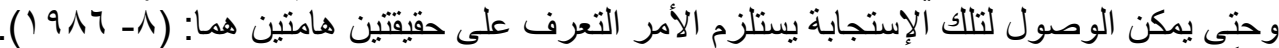

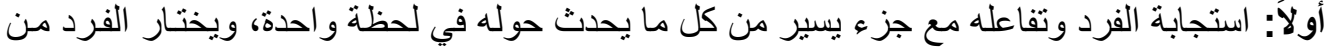

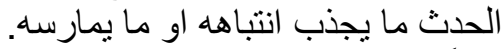
ثانياً: ان الخبرة الإدر اكية فردية تختلف من فرد إلي آخر وليست متنشابهة بين الأفر اد فالفرد بدرك في الئي

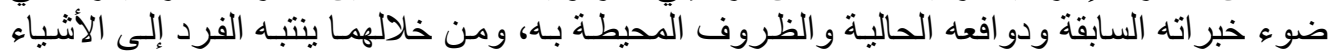

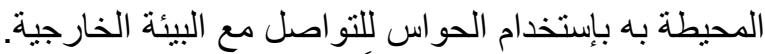

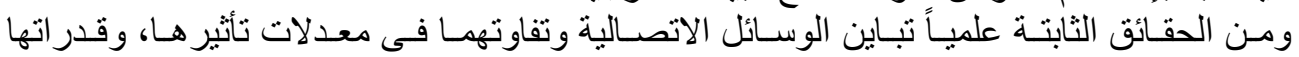

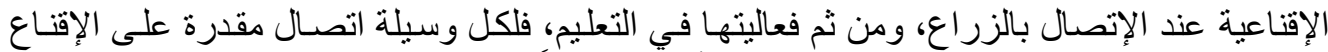

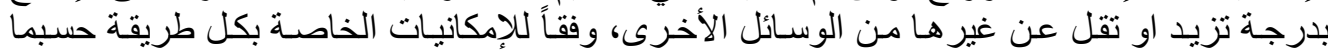

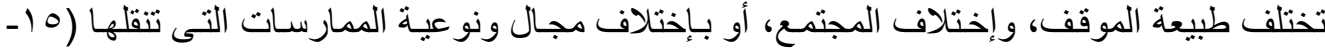

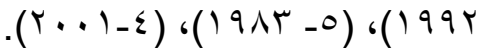
و أكدت نتائج الدراسات الإرشادية ذلك التباين بين تلك الطرق فى تأثير هـا على المسترشدين على هـ

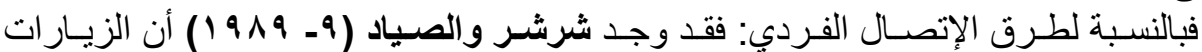
النحو التالى:

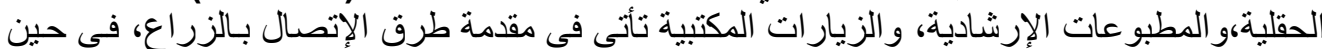

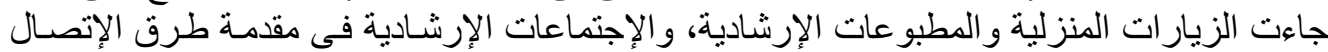

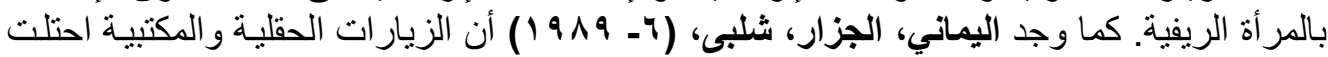

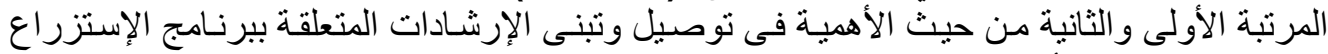

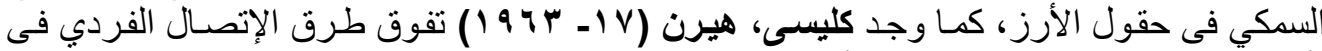

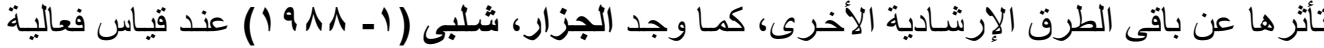

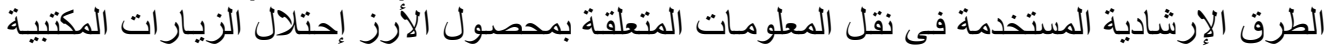

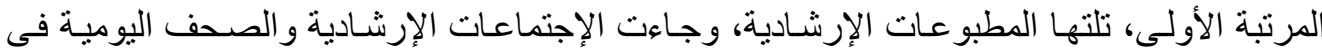

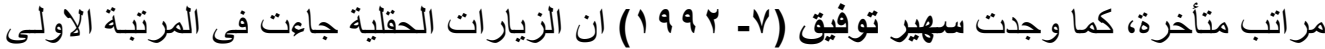

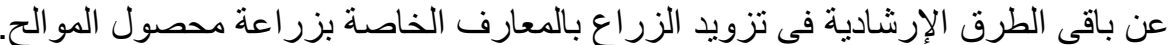
وبالنسبة لطرق الإتصال

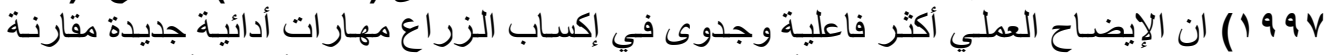

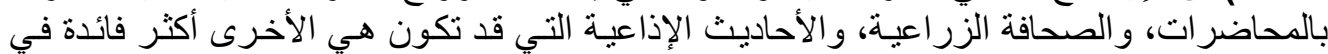

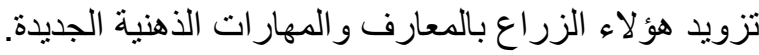

Fayoum J. Agric. Res. \& Dev., Vol.23, No.2, (B) July, 2009 


\section{7}

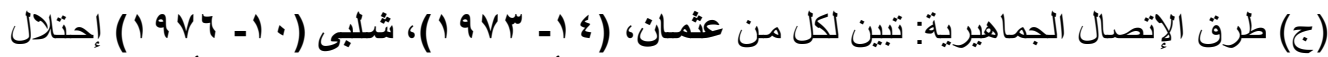

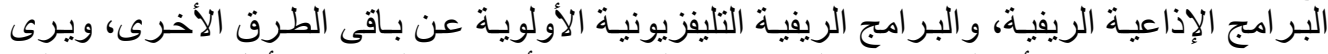

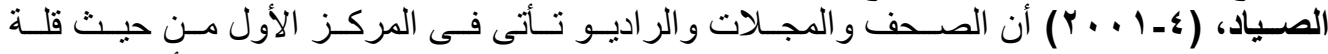

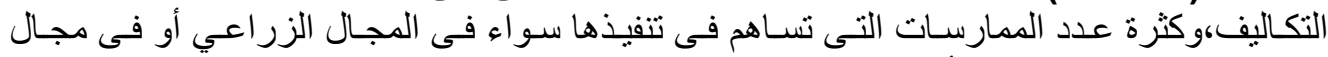

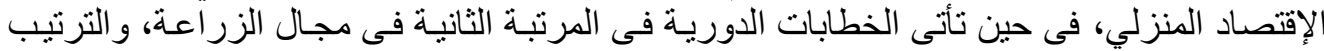

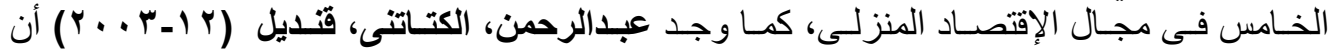

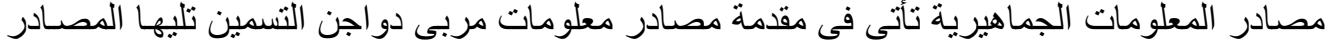
الفردية ثم الجماعية.

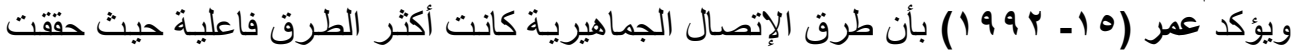

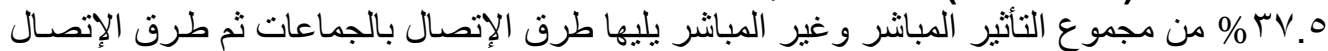

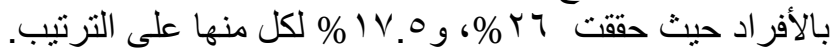

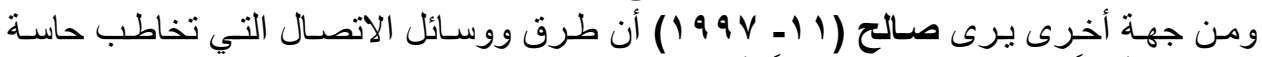

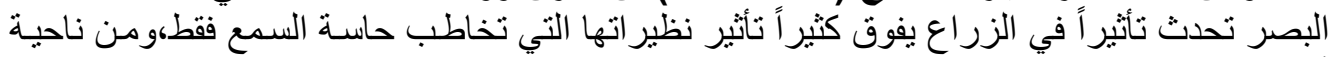

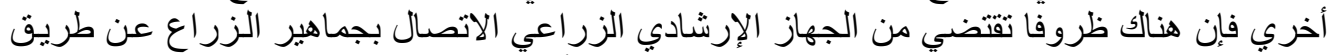

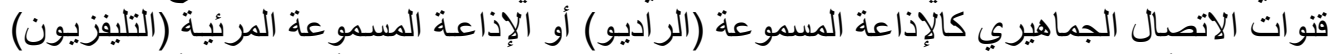

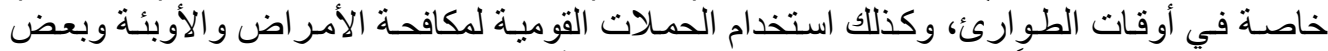

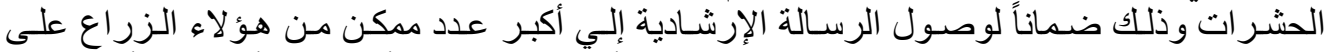

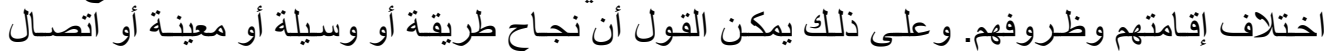

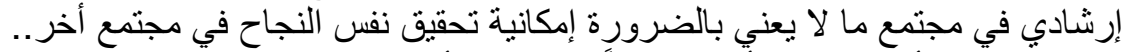

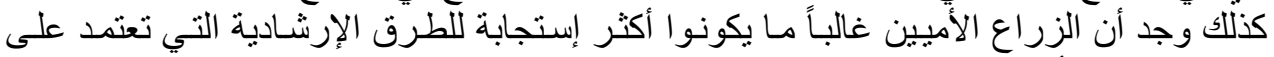

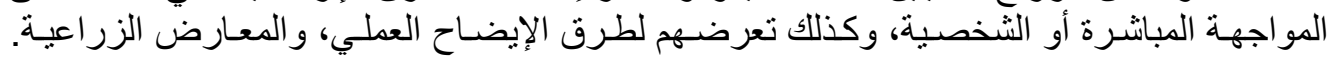

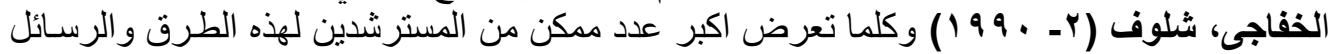

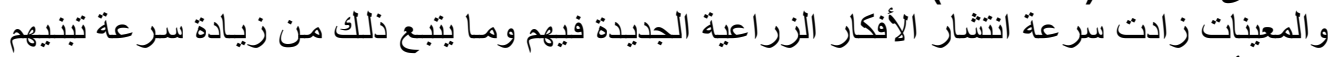

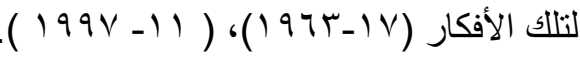

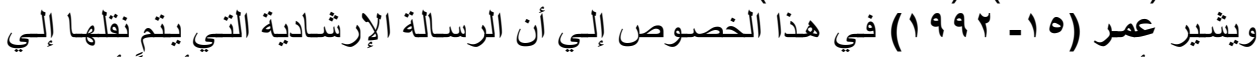

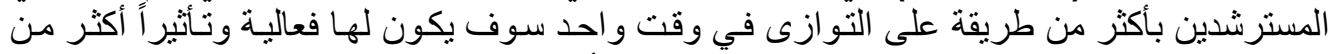

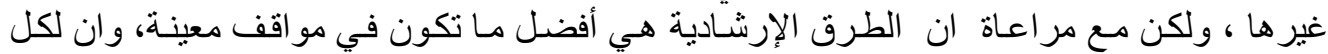

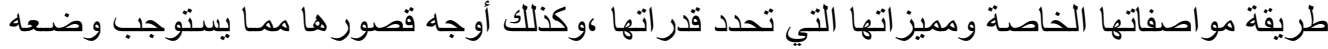

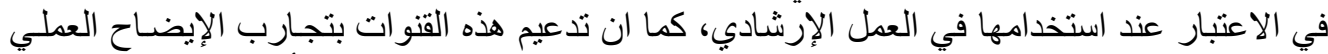

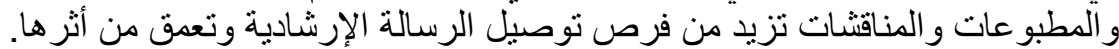

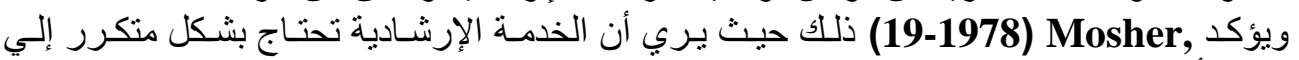

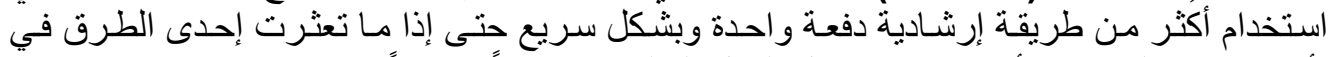

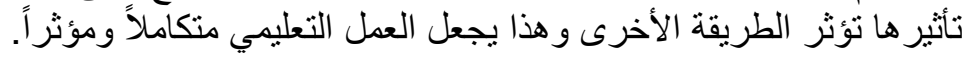

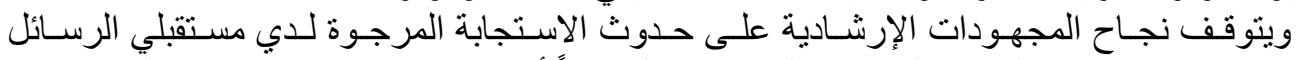

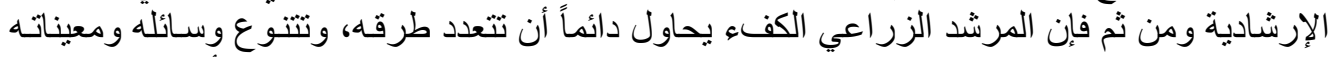

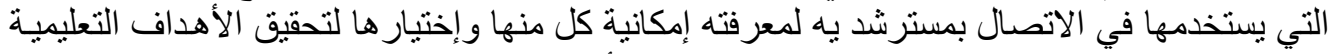

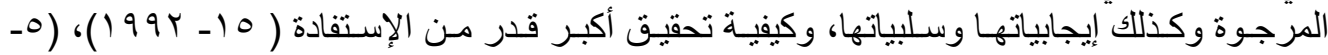
(199V-11) (1919r

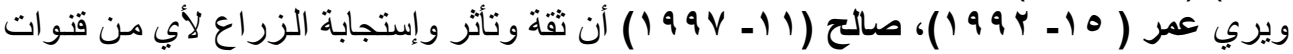

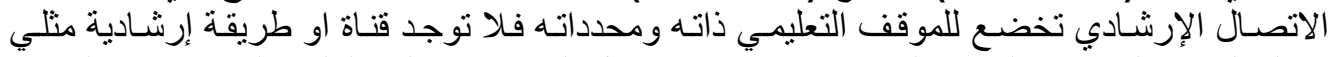

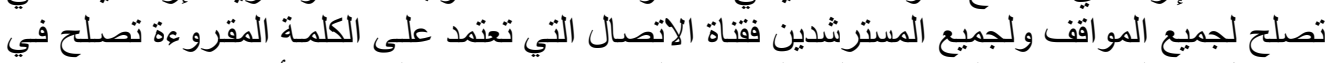

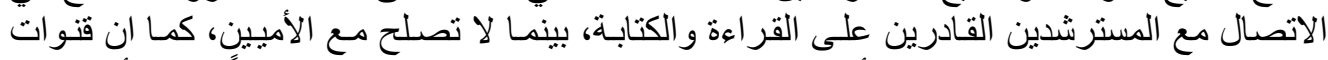

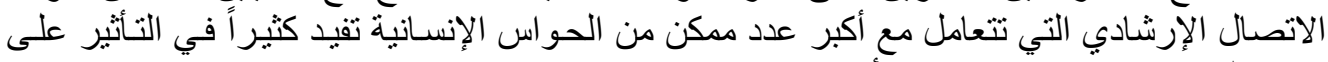
جميع المسترشدين بصفة عامة والأمئين الأمين منهم بصورة خاصة.

Fayoum J. Agric. Res. \& Dev., Vol.23, No.2, (B) July, 2009 


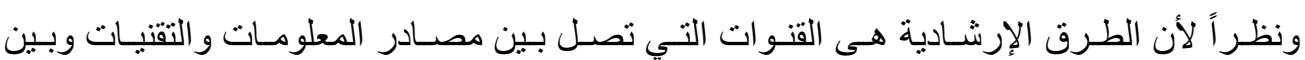

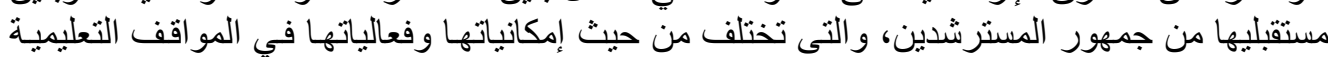

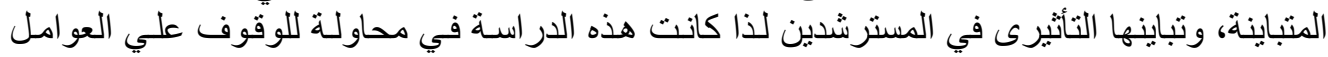

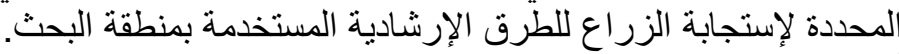

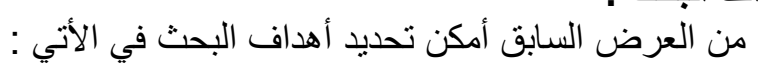

$$
\text { أهداف البحث : الإنجابة }
$$

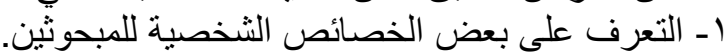

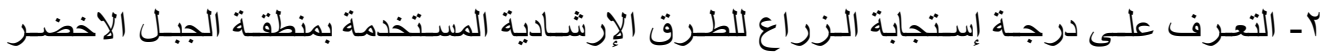

بالجماهيرية اللبيية.

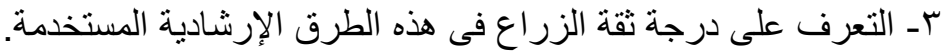

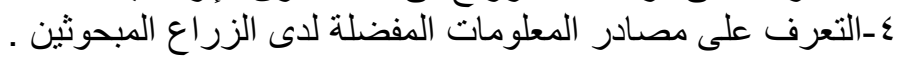

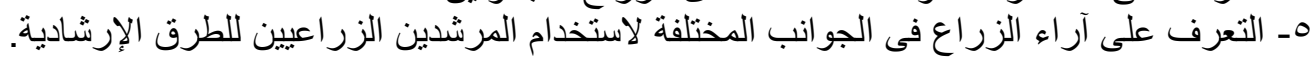

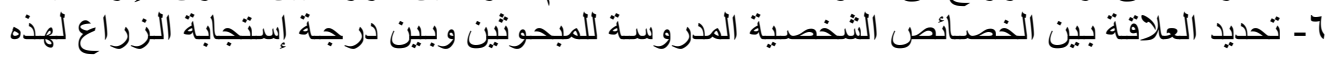

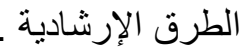

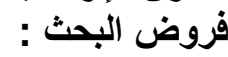

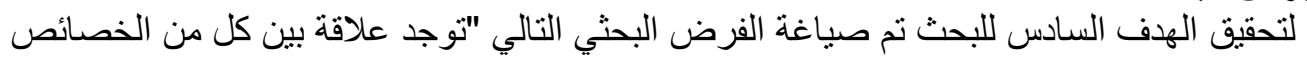

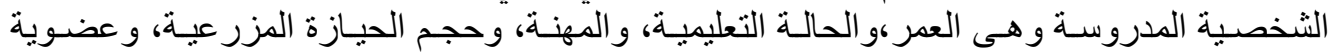

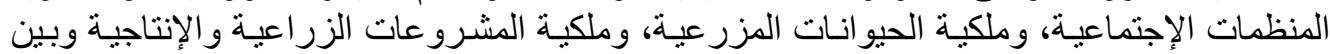

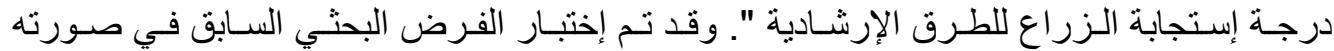

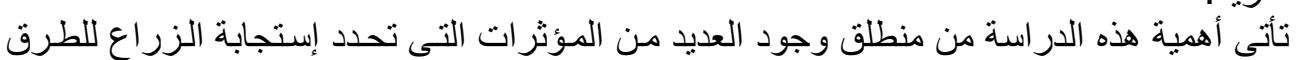
نأتى أهن:

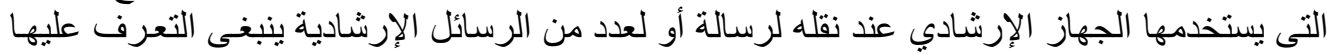

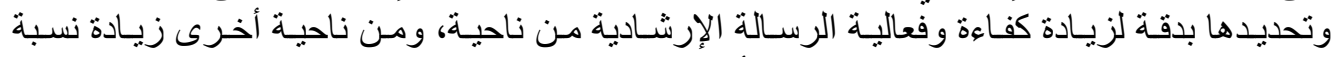

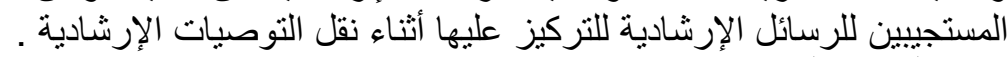

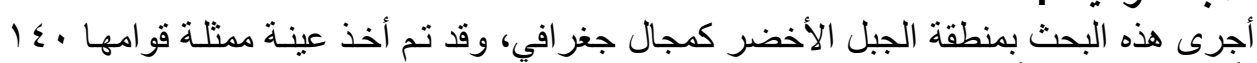

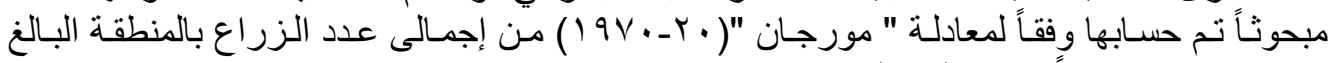

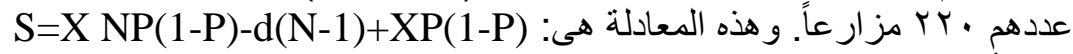
حيث أن : ( S تمثل حجم العينة المطلوب ( الحجم الأدنى للعينة).

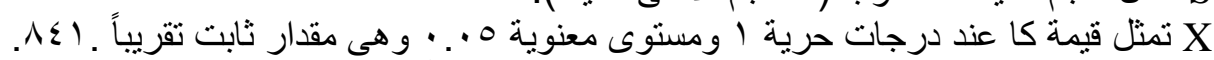

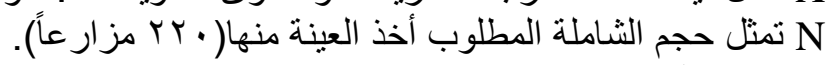

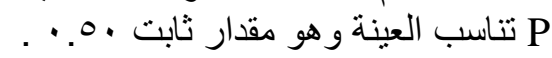

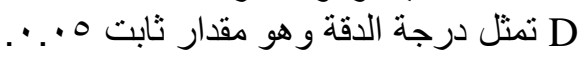

$$
\text { وطبقت المعادلة كالتالي: }
$$

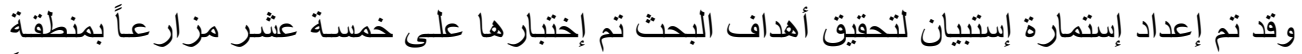

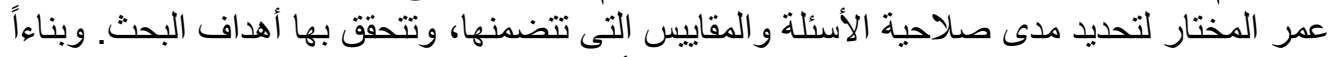

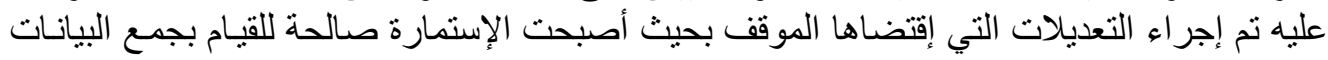

Fayoum J. Agric. Res. \& Dev., Vol.23, No.2, (B) July, 2009 


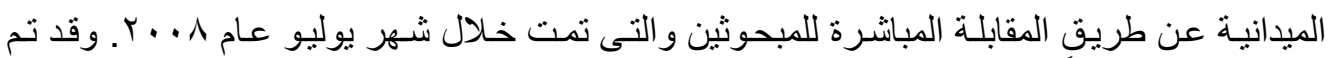

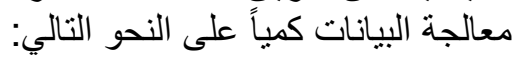

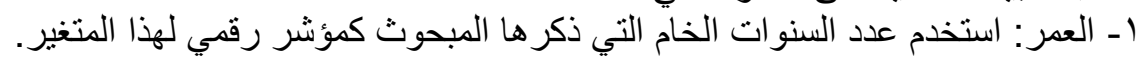

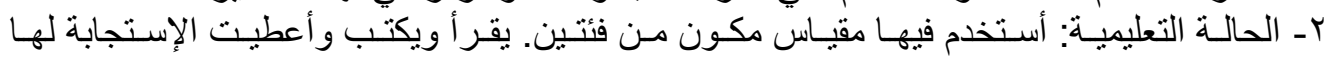

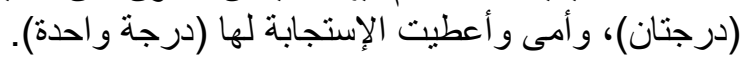

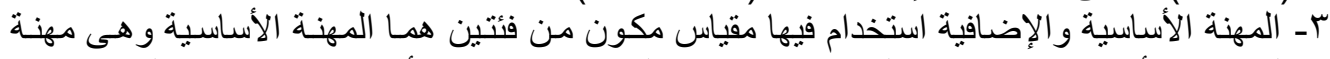

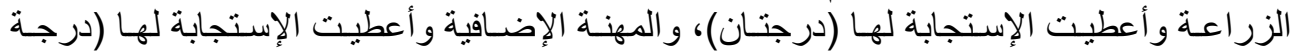
واحدة).

ع - حجم الحيازة المزرعية: أستخدم الهكتار ووحداته للتعبير عن حجم حيازته المزر عية.

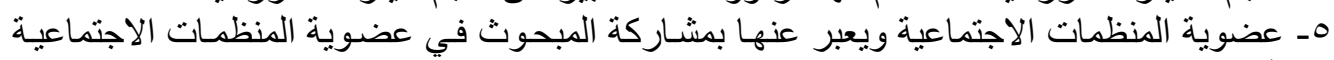

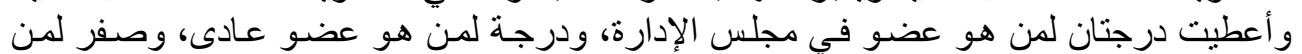
لاينتمى لعضوية أى منظمة إجتماعية.

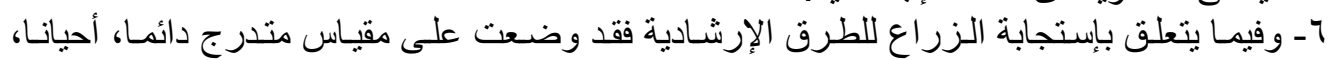

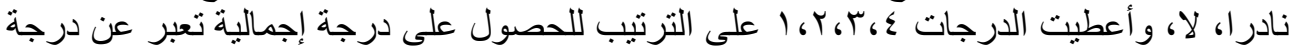

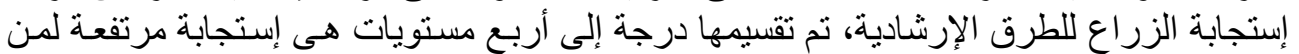

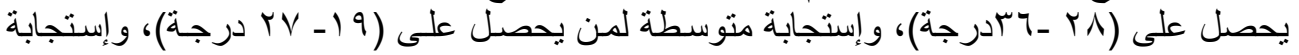

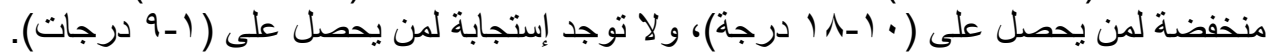

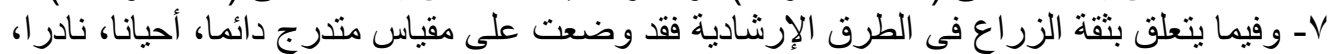

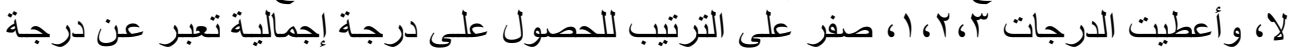

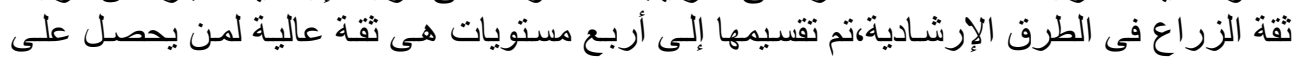

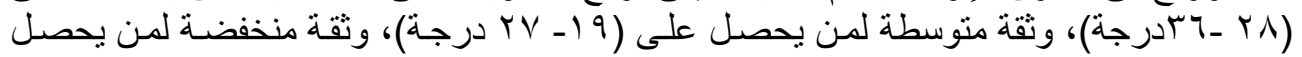

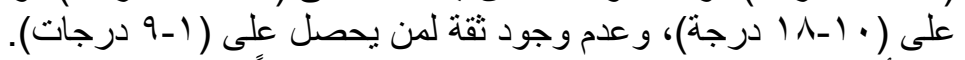

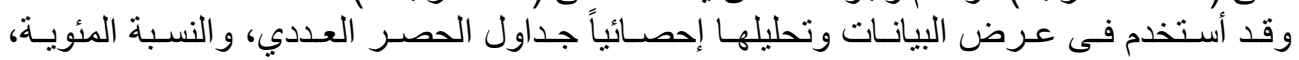

و المتوسط الحسابي، و التباين، و الانحر اف المعياري، ومعامل الإنل الإختلاف ومعامل الإرنباط البسيط. التعريفات الإجرائية: - الئية

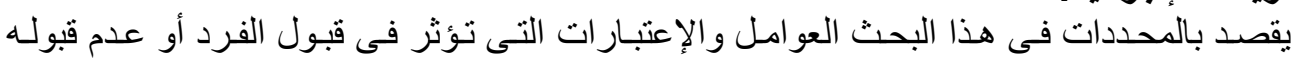
للطرق الإرشادية التى يستخدمها المرشدين الزراعين.

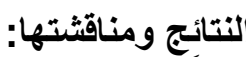 أولاً - وصف ومنفئنة: البحث:}

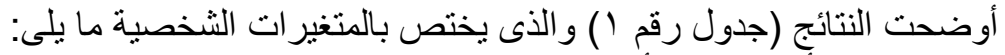

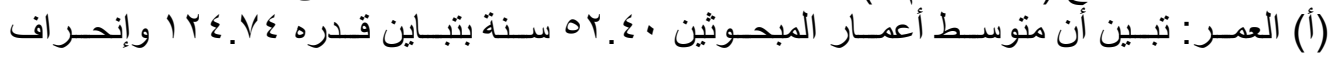

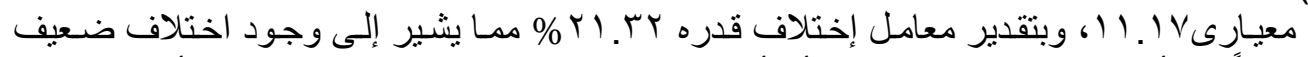

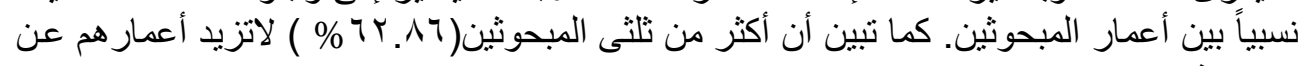
سنة 07

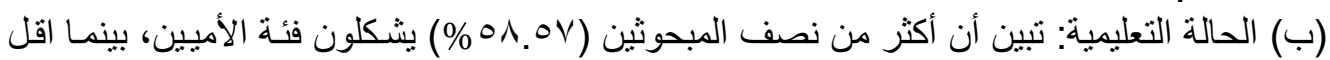

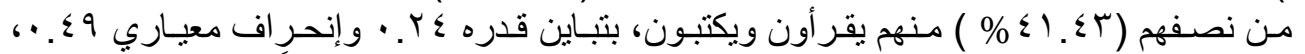

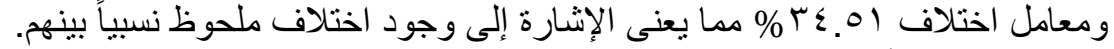

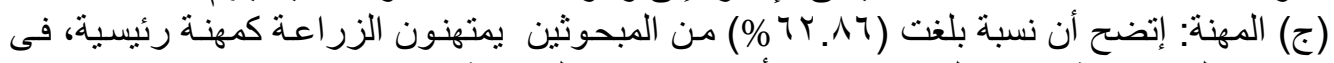

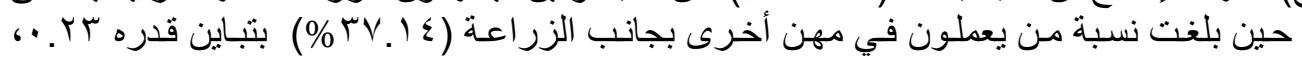

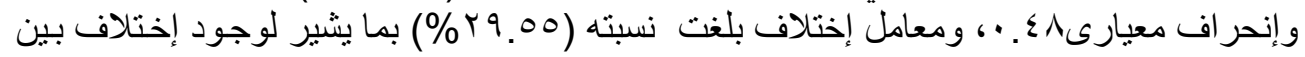

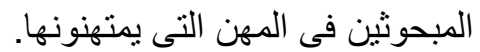

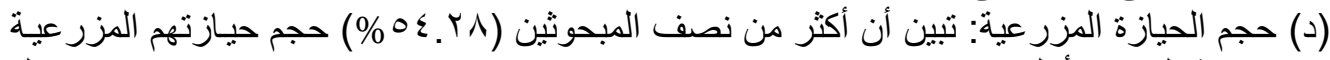

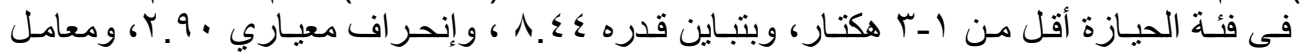

Fayoum J. Agric. Res. \& Dev., Vol.23, No.2, (B) July, 2009 


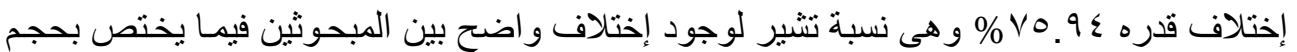
الحيازة المزر عية.

(ه) عضوية المنظمات الإجتماعية: وجد أن أن أكثر من نصف المبحوثين أعضاء في منظمات إجتماعية

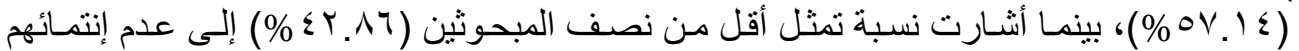

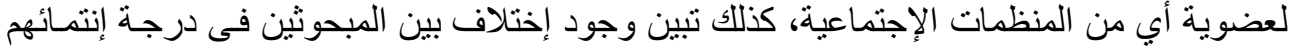

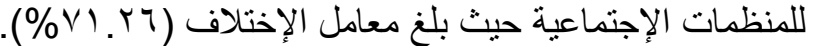

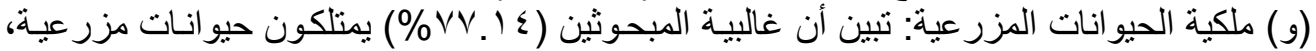

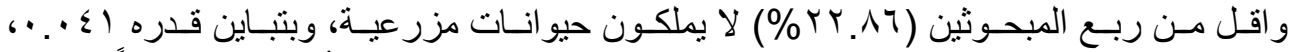

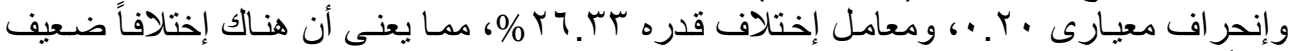
نسبياً بين المبحوثين.

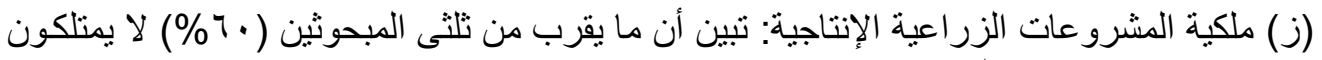

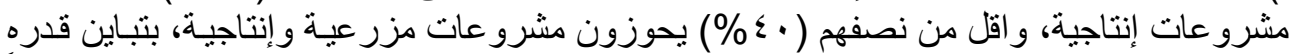

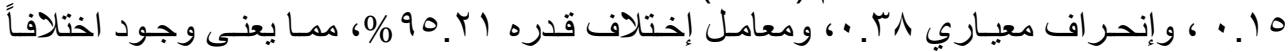

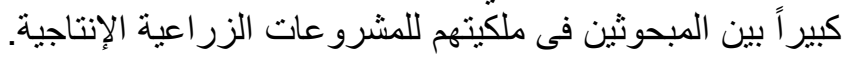

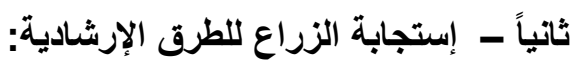

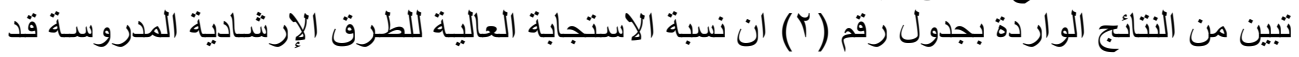

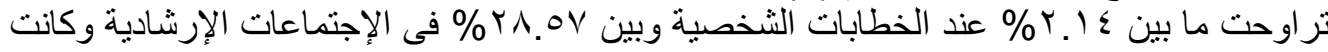

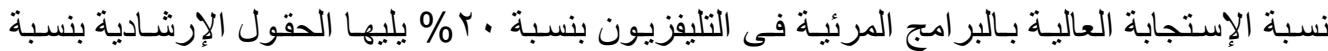

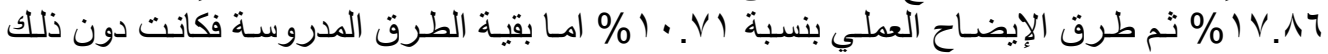

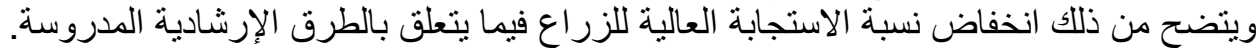

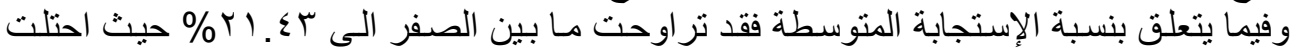

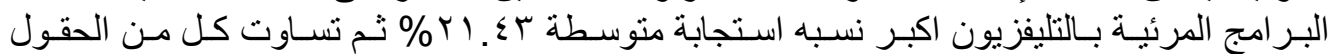

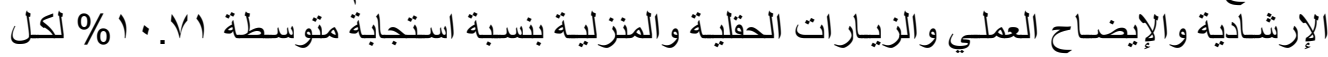

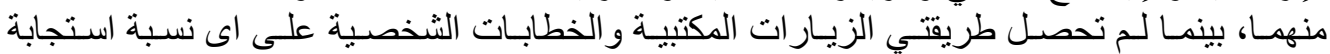
متوسطة.

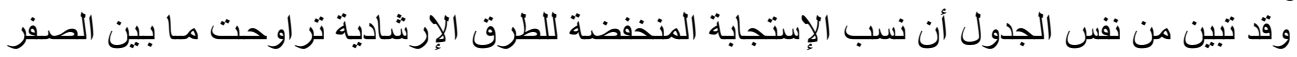

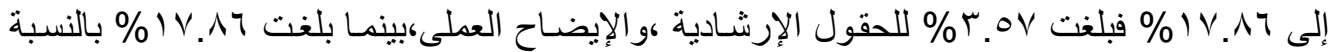

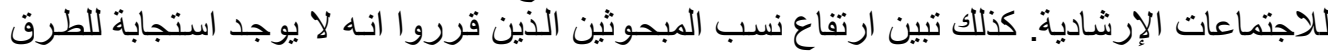

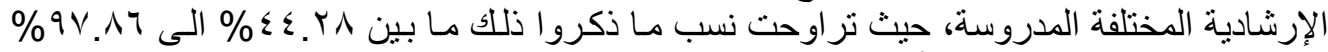
و هذا يوضح ان غاليية الزراع أقروا بعدم وجود استجابة للطرق الإرشادية التى يستخدمها المرشدون

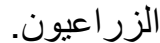

وبصفة عامة يتضح إنخفاض نسب إستجابة الزراع لكافة الطرق الإرشـادية المستخدمة وبترتيبها

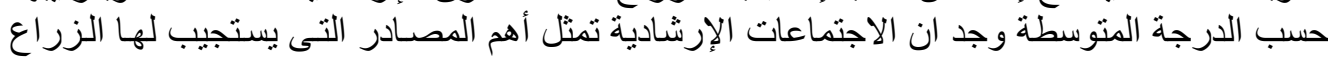

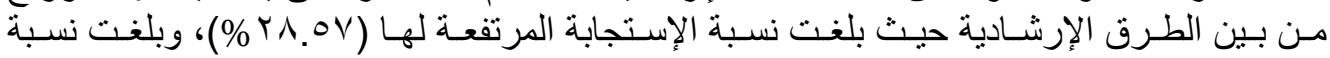

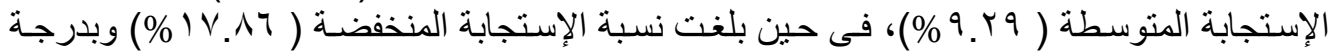

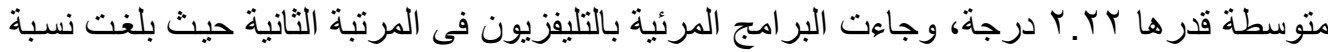

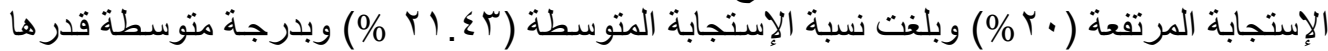

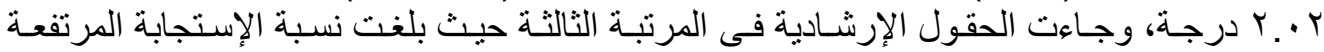

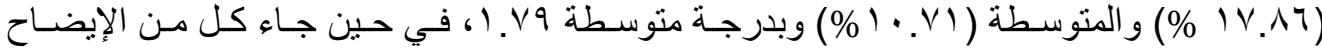

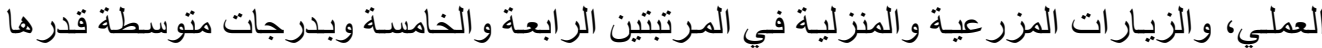

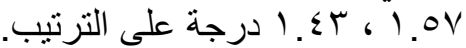

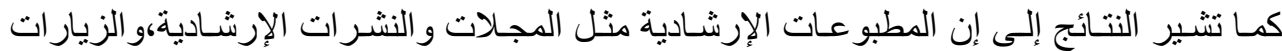

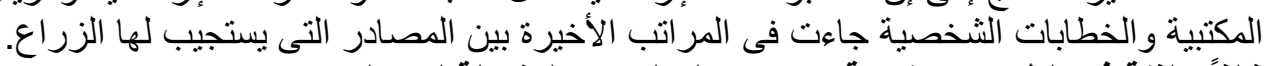
ثالثاً: الثقة فى الطرق الإرشادية ومصادر المطلومات المفضلة لدى الزراع الثراع :

Fayoum J. Agric. Res. \& Dev., Vol.23, No.2, (B) July, 2009 
$1 \%$.

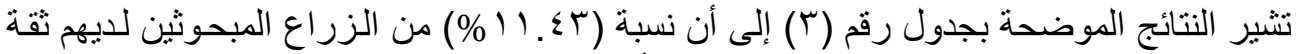

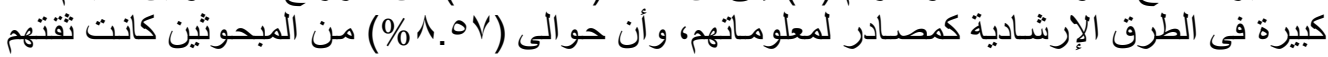

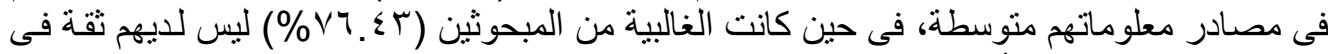

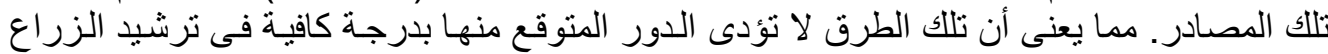

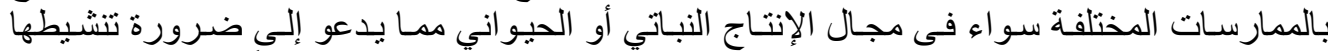

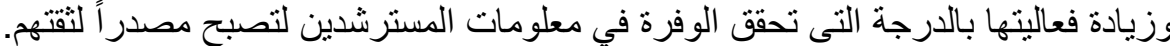

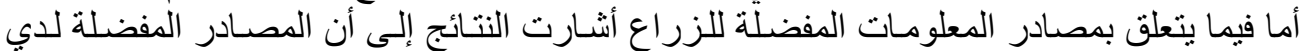

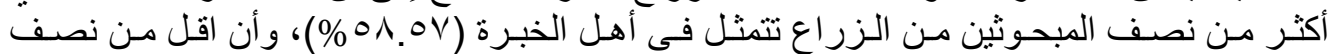

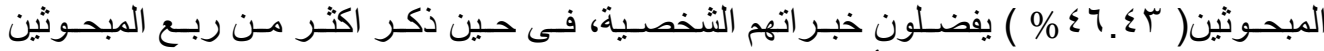

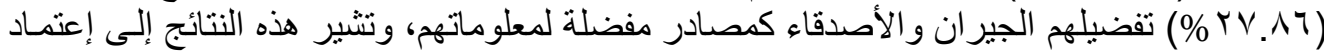

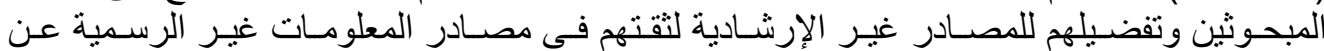

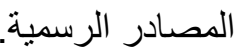
رابعاً: آراء الزراع في الرئة الطرق الإرشادية الثائعة التى يستخدمها المرشد الزراعي:

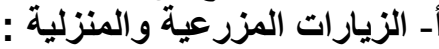

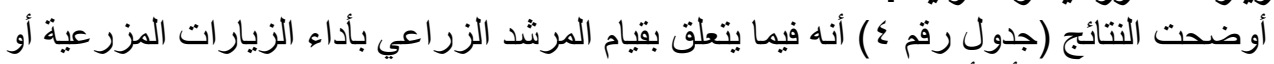

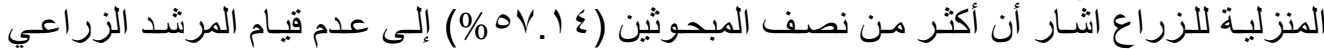

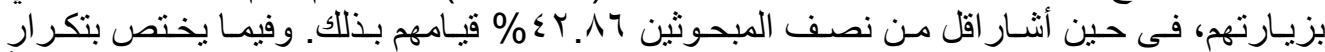

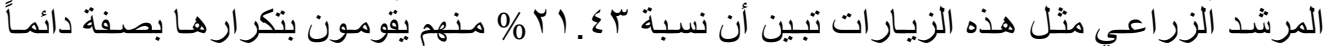

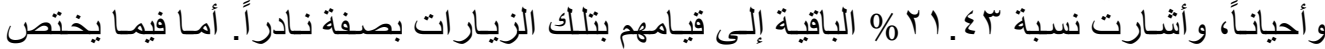

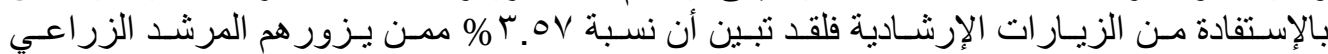

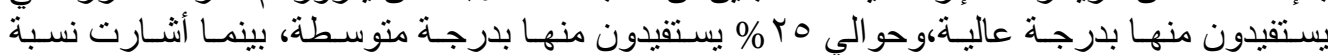

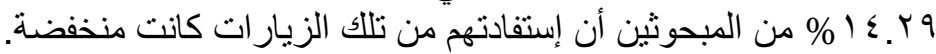

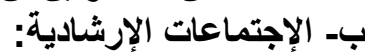

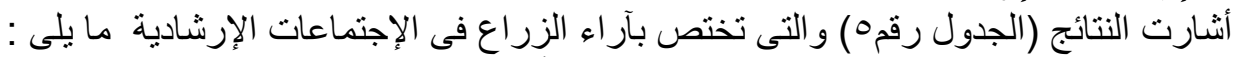

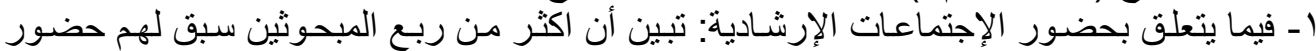

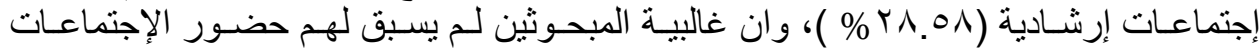

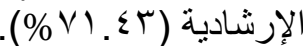

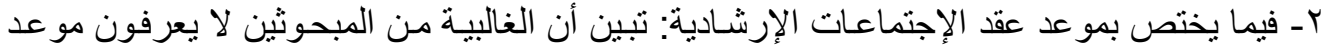

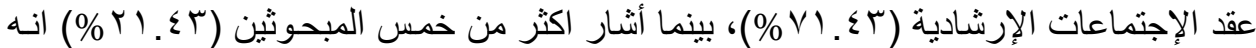
يتم عقدها في الفترة الصباحية.

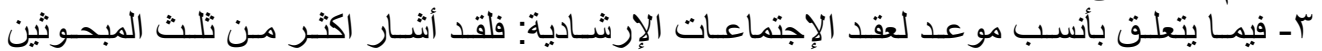

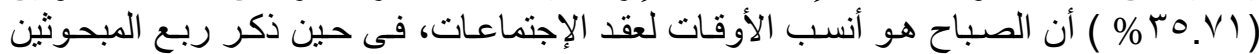

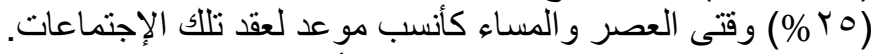
ع- وفيما يتعلق بمدى إنتظام الإجتماعات: فقد أثنار اكثر من ربع المبحوثين (YY.OV\%) إلى أنها تعقد بصفة منتظمة.

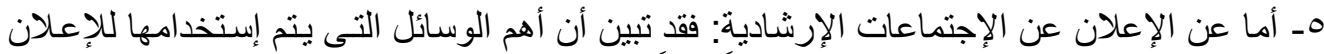

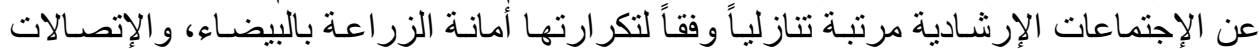

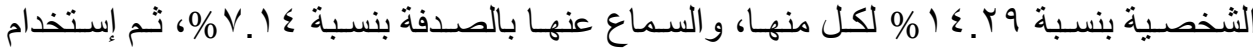

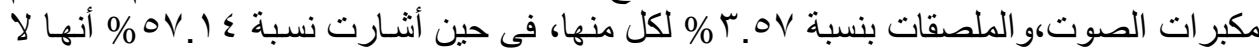
تعرف عن هذه الإجتماعات شيئًا.

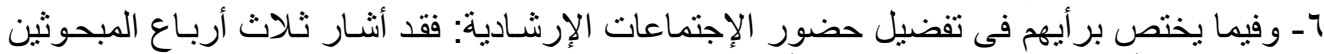

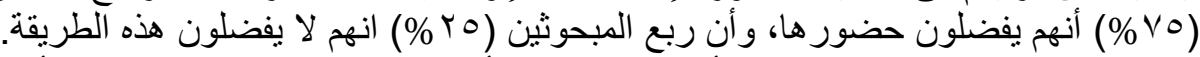

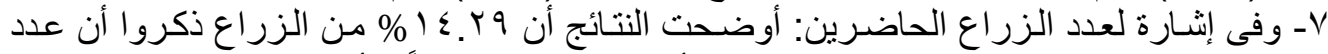

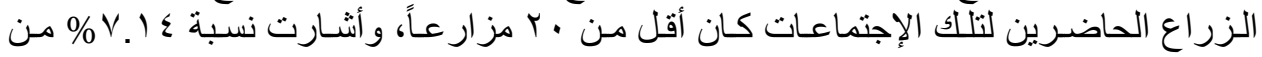

Fayoum J. Agric. Res. \& Dev., Vol.23, No.2, (B) July, 2009 


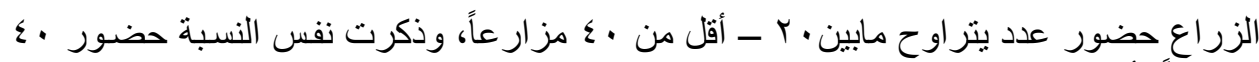
مز ارعاً فأكثر.

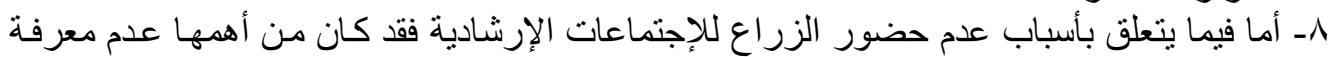

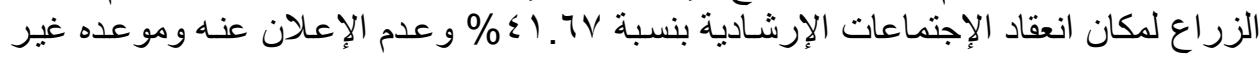

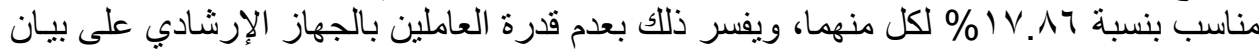

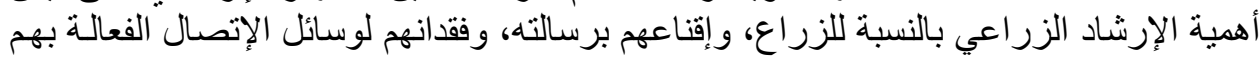

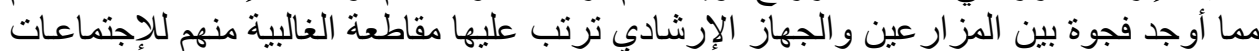

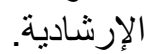

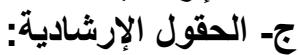

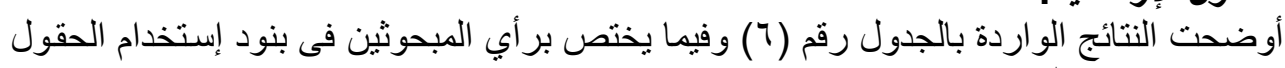

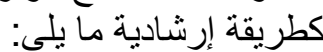

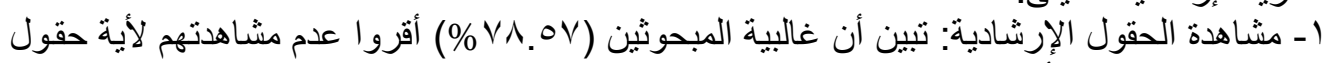

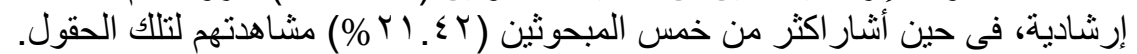

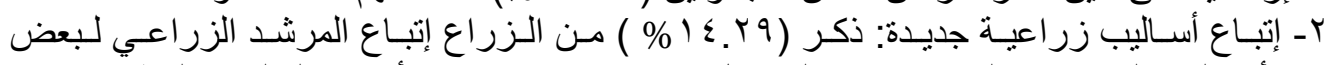

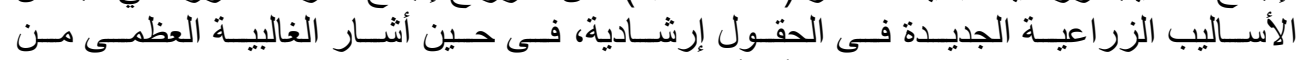

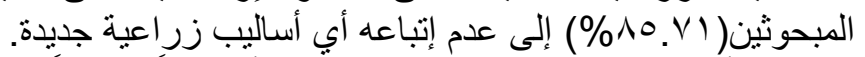

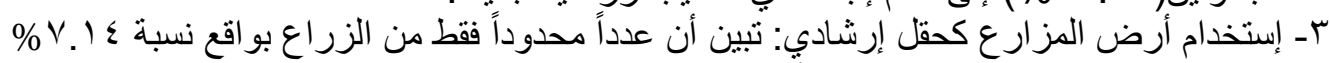

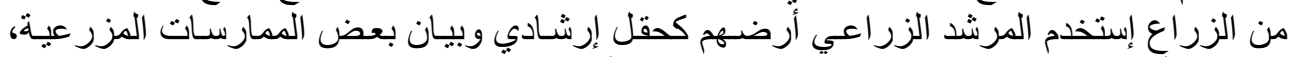

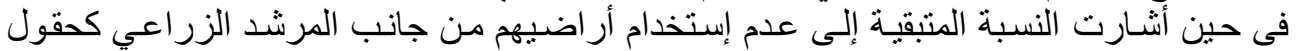
إرشادية.

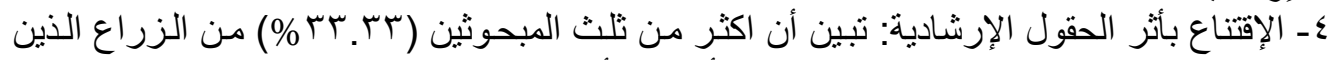

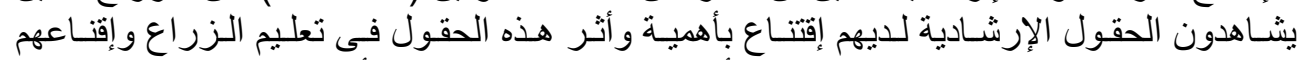

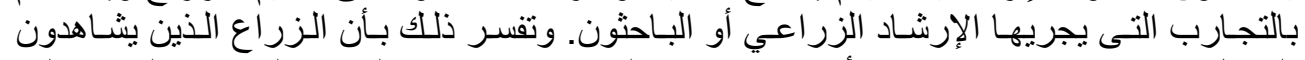

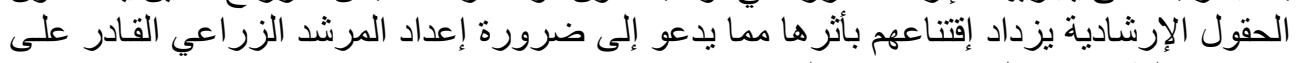

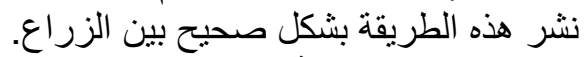

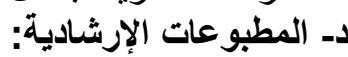

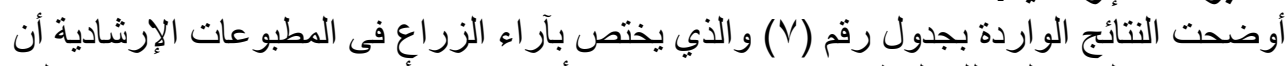

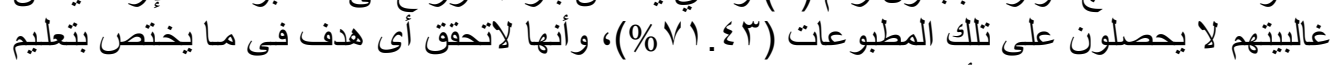

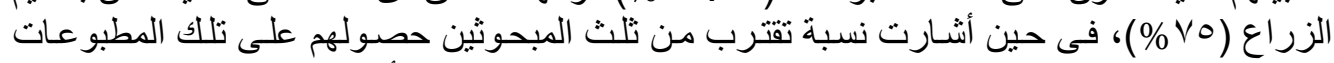

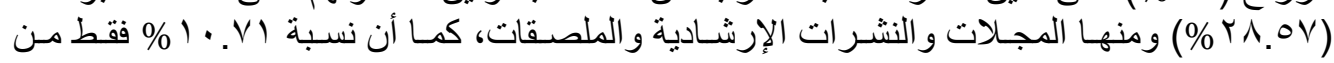

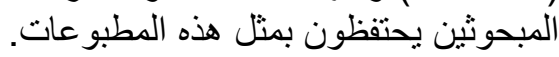

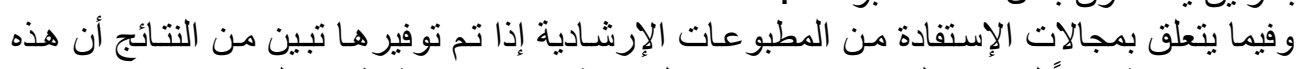

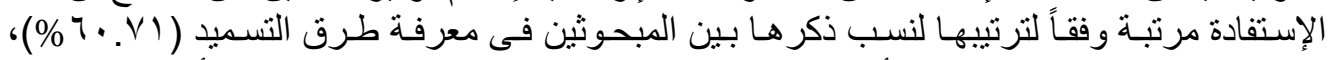

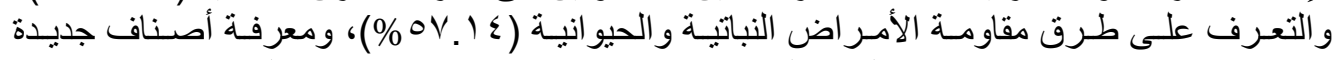

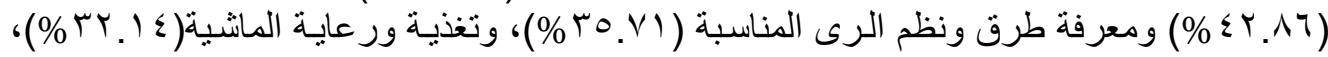

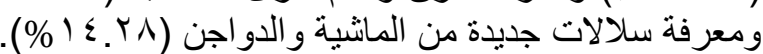

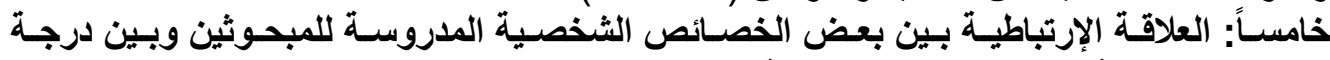

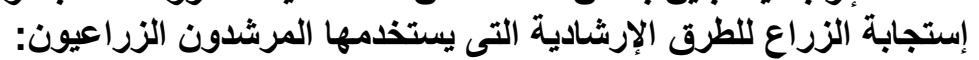

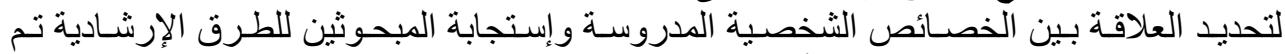

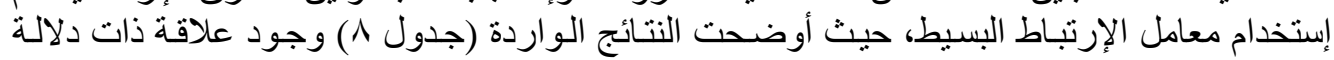

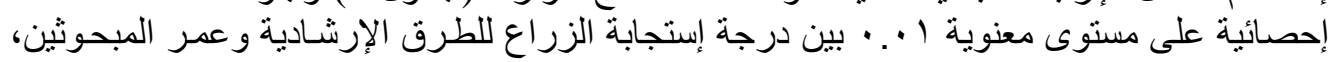

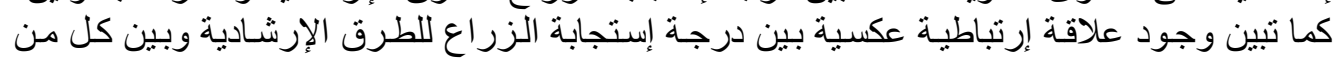

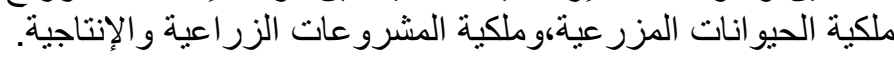
التوصيات:

Fayoum J. Agric. Res. \& Dev., Vol.23, No.2, (B) July, 2009 
فى ضو ء ما أسفرت عنه نتائج الدر اسة يمكن الخروج بالتوصيات التالية:

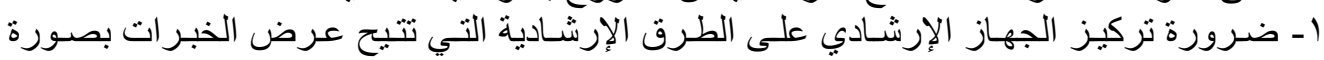

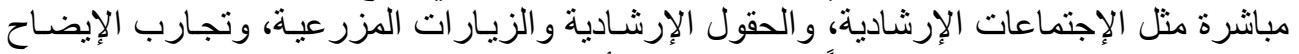

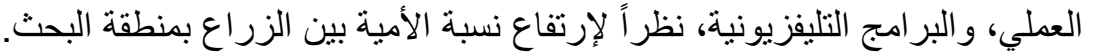

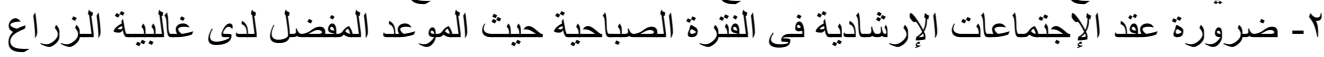

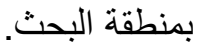
r- ضرورة إستعانة المرشدين الزر اعيين بـالزراع ذوى الخبرة،و الجيران و الأصدقاء عند إستخدام

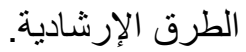

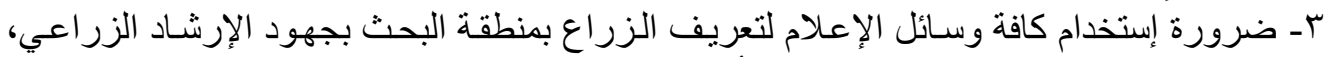

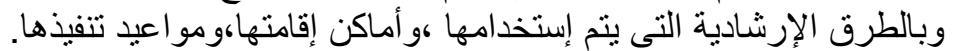

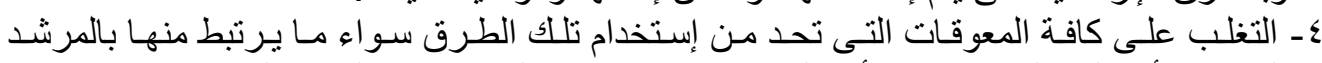

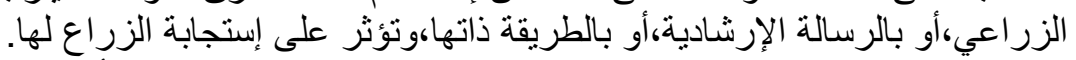

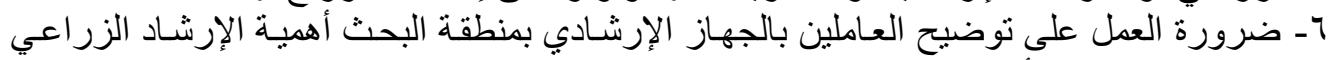
للزراع ، و وإقناعهم بأهمية الطرق توضع التي يستخدمها.

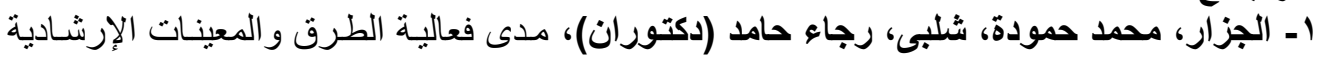

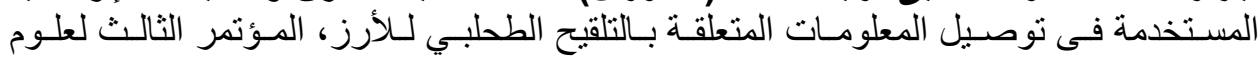

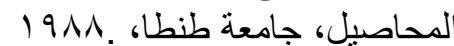

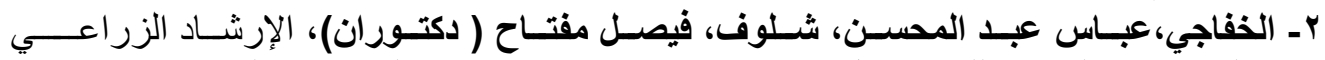

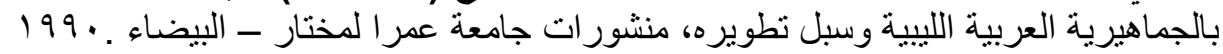

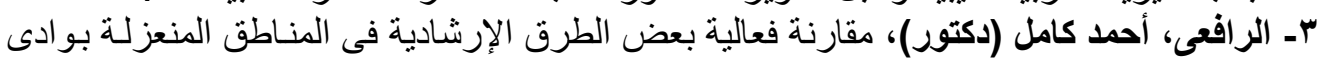

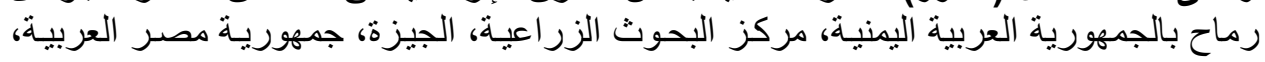
$19 \times 9$ ع ـ الصبياد، عبد الباسـ محمـد (دكتور)، الطـرق و المعينـات الإرشـادية، مصـر للخدمات العلميـة،

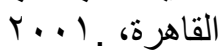

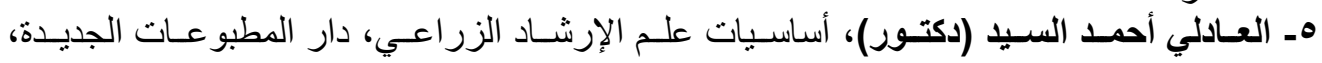

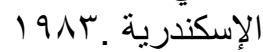

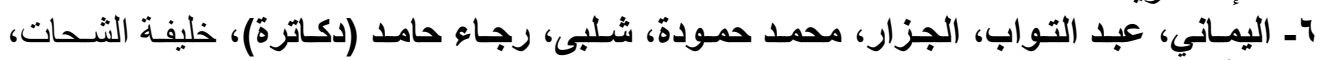

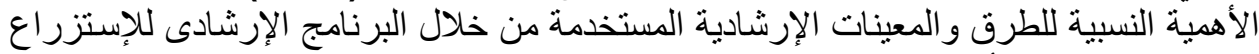

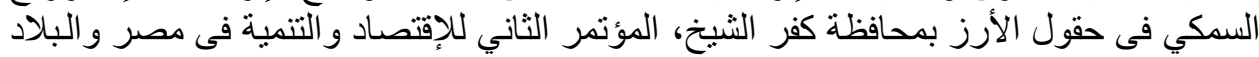

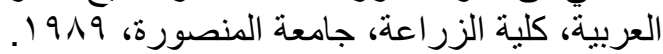

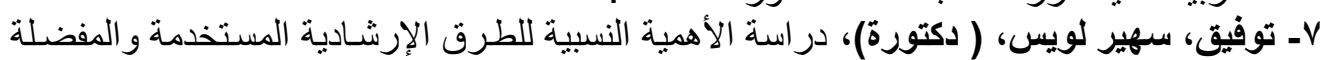

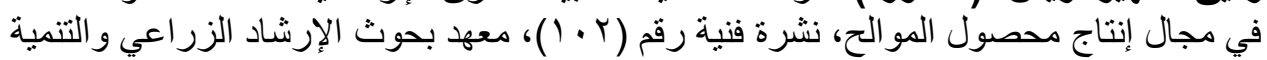

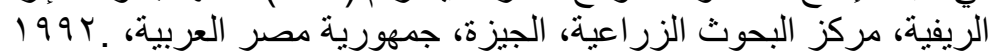

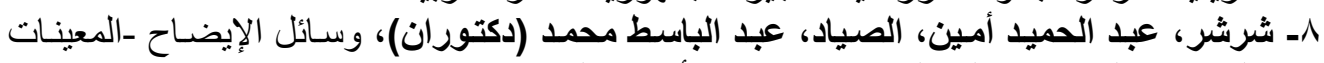

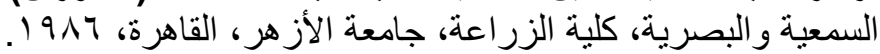

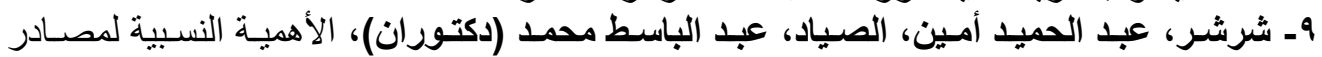

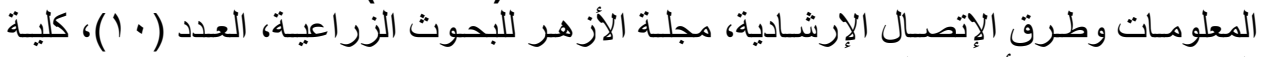

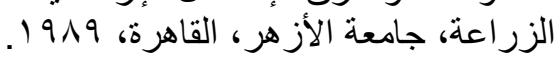

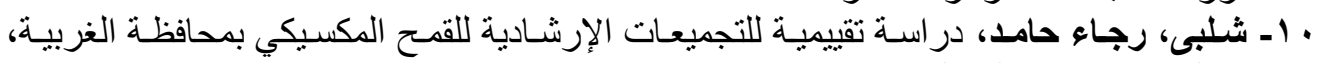

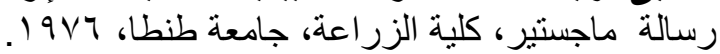

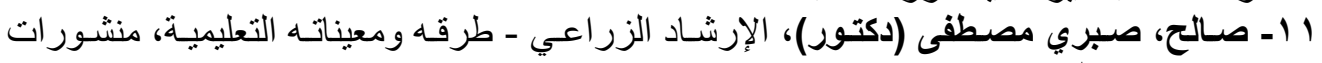

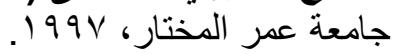

Fayoum J. Agric. Res. \& Dev., Vol.23, No.2, (B) July, 2009 
Y ا - عبد الرحمن، عبد المنعم محمد، الكتاتنى، أحمد محمـود، قنديل، ممدوح شعبان (دكـاترة)،

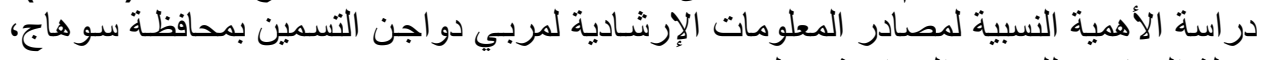

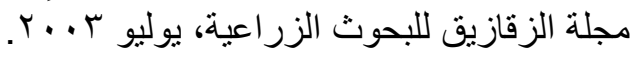

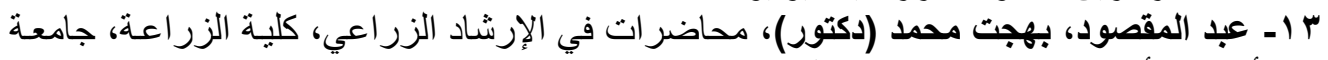

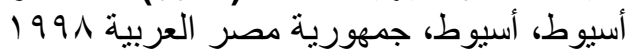

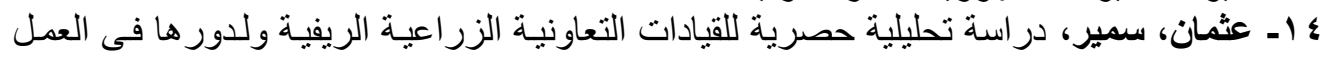

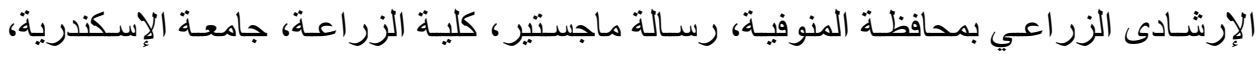
19Vr

1 اـ عمـر، أحمد محمد (دكتور)، الإرشـاد الزراعي المعاصـر، مصر للخدمات العلميـة، القـاهرة 1994

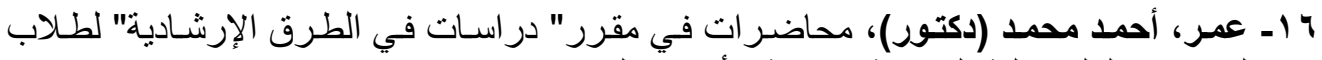

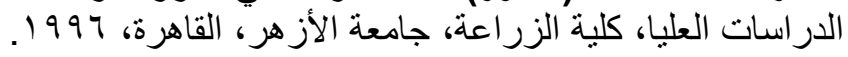

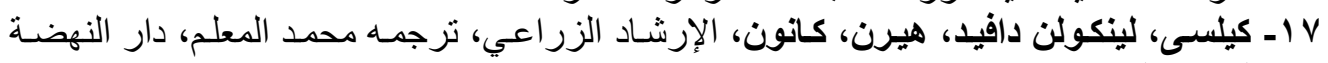

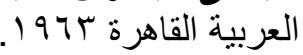

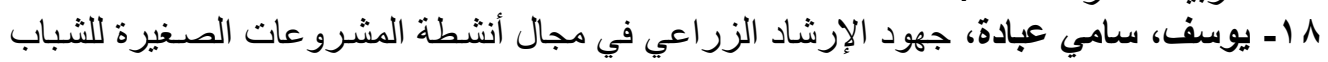

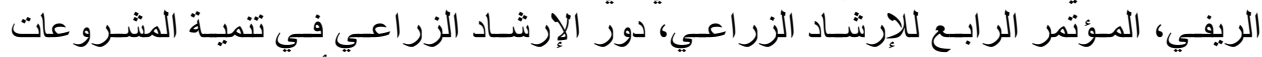

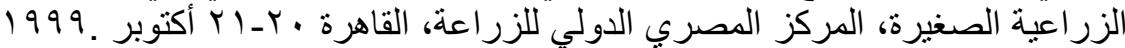

19- Mosher, A.T., An introduction Agricultural Extension, Agricultural Development Council, New York,1978.

20- R.V, Kregcie, \& D.W, Morgan, Educational and Psychological Measurement, College Station, Durham North Carolina, U.S.A, Vol (30), 1970, PP 62-63.

جدول رقم (1) توزيع المبحوثين وفقاً لخصائصهم الثخصية.

\begin{tabular}{|c|c|c|c|c|c|c|c|}
\hline الإختلافل & المعيارى الإنحر & التباين & المتوسط & $\%$ & عدد* & \multicolumn{2}{|c|}{ الخصائص } \\
\hline \multirow{3}{*}{ rI.rr } & \multirow{3}{*}{$11.1 \mathrm{~V}$} & \multirow{3}{*}{ IY.VE } & \multirow{3}{*}{ Or.s. } & $1 V .1 \leq$ & Y & منVYr- I؛ سنة & \multirow[t]{3}{*}{ العمر } \\
\hline & & & & $\leqslant 0 . v 1$ & $7 \leqslant$ & من Y ؟ --- צ سنة & \\
\hline & & & & $r V .1 \varepsilon$ & $O r$ & 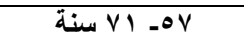 & \\
\hline \multirow{2}{*}{$r \varepsilon . v_{0}$} & \multirow{2}{*}{$\cdot . \$ 9$} & \multirow{2}{*}{$\because r \leqslant$} & \multirow{2}{*}{$1 . \leqslant r$} & $\Delta \wedge . \Delta V$ & Ar & أمى & \multirow[b]{2}{*}{ الحالة التعليمية } \\
\hline & & & & $\varepsilon 1 . \leqslant \mu$ & 01 & يقرأ ويكتب & \\
\hline \multirow{2}{*}{$r 9.00$} & \multirow{2}{*}{$\cdot . \leqslant \wedge$} & \multirow{2}{*}{$\cdot r^{r}$} & \multirow{2}{*}{$1.7 r$} & ૧Y.A & $\Lambda \wedge$ & الأساسية (مزارع ) & \multirow[t]{2}{*}{ المهنة } \\
\hline & & & & $r v .1 \leq$ & $O Y$ & إضافية بجاتب الزراعة & \\
\hline \multirow{3}{*}{$v 0.9 \leq$} & \multirow{3}{*}{ r.q. } & \multirow{3}{*}{$\Lambda . \leqslant \leqslant$} & \multirow{3}{*}{ r.Aro } & $0 \leqslant . Y \wedge$ & 87 & أقل من ا-ب هكتار & \multirow{3}{*}{ المزرعية الحيازة } \\
\hline & & & & YY.AY & rY & من ء ـ أقل من V هكتار & \\
\hline & & & & YY.AT & $r r$ & هكتار فَأكثر & \\
\hline \multirow{3}{*}{ VI.YT } & \multirow{3}{*}{$\because \leqslant 9$} & \multirow{3}{*}{$\cdot r \leqslant$} & \multirow{3}{*}{. .79} & $11 . \leqslant r$ & 17 & عضو مجلس إدارة & \multirow{3}{*}{ الإجتماعية المنظمات } \\
\hline & & & & $20 . V 1$ & $7 \varepsilon$ & عضو عادى & \\
\hline & & & & 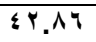 & 7. & غير عضو & \\
\hline \multirow{2}{*}{ rצ.rr } & \multirow[b]{2}{*}{$\because r}$. & \multirow[b]{2}{*}{$\because \leqslant 1$} & \multirow[b]{2}{*}{$\because V \vee$} & $V V .1 \leq$ & 1.1 & يملك & \multirow{2}{*}{ المزية الحيوانات } \\
\hline & & & & YY.AT & rr & لايملك & \\
\hline \multirow{2}{*}{90.41} & \multirow{2}{*}{$\cdot . r \Lambda$} & \multirow{2}{*}{.10} & \multirow{2}{*}{$\because \varepsilon \cdot$} & $\varepsilon$ & 04 & يملك & \multirow{2}{*}{ الزرية العية والإتتاجية } \\
\hline & & & & 7. & $\Lambda \varepsilon$ & لايملك & \\
\hline
\end{tabular}

جدول رقم (Y) توزيع المبحوثين وفقاً لدرجة إستجابتهم لإستخدام الطرق الإرشادية.

Fayoum J. Agric. Res. \& Dev., Vol.23, No.2, (B) July, 2009 


\begin{tabular}{|c|c|c|c|c|c|c|c|c|c|c|}
\hline \multirow{3}{*}{ 牙: } & \multirow{3}{*}{$\begin{array}{l}\overline{7} \\
\overline{7} \\
\overline{3} \\
\overline{3}\end{array}$} & \multicolumn{8}{|c|}{ درجة إستجابة الزراع للطرق الإرشادية } & \multirow{3}{*}{ الطرق الإرشادية } \\
\hline & & \multicolumn{2}{|c|}{ (1 - لاج إستات) } & \multicolumn{2}{|c|}{ (إستجابة منخفضة 1 ا درجة) } & \multicolumn{2}{|c|}{ (إبتجابة متوسطة } & \multicolumn{2}{|c|}{ 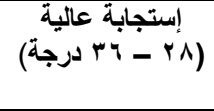 } & \\
\hline & & $\%$ & عدد & $\%$ & ع عدد & $\%$ & عدد & $\%$ & عدد* & \\
\hline$r$ & 1.19 & TV.AT & 90 & $r . \Delta V$ & 0 & $1 \cdot . v 1$ & 10 & $1 V . \wedge 7$ & ro & الحقول الإرشادية \\
\hline$r$ & Y.Pr & $\bullet \wedge . \diamond \vee$ & Ar & - & - & $r . \leqslant r$ & $r$ r. & $r \cdot$ & YA & الإذاعة المرئية \\
\hline 7 & $1 . r \varepsilon$ & AV.I $1 \leq$ & IYY & - & - & $\varepsilon . Y \wedge$ & 7 & $\Lambda . \diamond \mathrm{V}$ & Ir & المطبوعات الإرشادية \\
\hline$\wedge$ & 1.10 & 90 & Irr & - & - & - & - & 0 & $\mathrm{~V}$ & الزيارات المكتبية \\
\hline$\varepsilon$ & $1.0 \mathrm{~V}$ & vo & 1.0 & $r .01$ & 0 & $1 \cdot . v 1$ & 10 & $1 \cdot . v 1$ & 10 & الإيضاح العملى \\
\hline 9 & 1.9 & 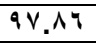 & $1 T V$ & - & - & - & - & Y.I & $r$ & الخطابات الثخصية \\
\hline $\mathrm{V}$ & $1 . r 1$ & AY.I & 110 & $\vee . \wedge 7$ & 11 & V. $1 \leqslant$ & 1. & r.A & $\varepsilon$ & الإذاعة المسموعة \\
\hline 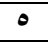 & $1 . \leqslant r$ & AY.IE & 110 & - & - & $1 \cdot . v 1$ & 10 & V.I & 1. & الزيارات المزرعية والمنزلية \\
\hline 1 & Y.YY & $\varepsilon \varepsilon . Y \wedge$ & $4 r$ & $1 V . \wedge 4$ & ro & 9.19 & 14 & $r \wedge .0 V$ & $\xi \cdot$ & الإجتماعات الإرشادية \\
\hline
\end{tabular}

جذول رقم (ץ) توزيع المبحوثين وفقاً لارجة ثقتهم فى مصادر معلوماتهم ،وآرائهم فى المصادر المفضلة لمعلوماتهم.

\begin{tabular}{|c|c|c|c|}
\hline$\%$ & عدد* & \multicolumn{2}{|c|}{ آراء الزراع } \\
\hline 11.24 & 17 & 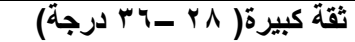 & \multirow{5}{*}{ درجة الثقة فى الطرق الإرشادية } \\
\hline$\Lambda . \diamond \mathrm{V}$ & Ir & ثقة متوسطة ( 9 rV_ & \\
\hline r.OV & 0 & ثقة منخفضة ( • ( 1 ( درجة) & \\
\hline$V 7 . \leqslant r$ & $1 \cdot v$ & لا توجد ثقة ( 1 (- 9 درجة) & \\
\hline $1 \cdots$ & $1 \leq$ & المجموع & \\
\hline $0 \wedge .0 \mathrm{~V}$ & AY & أهل الخبرة & \multirow[t]{3}{*}{ المصادر المفضلة لمعلوماتهم } \\
\hline$\leqslant 7 . \leqslant r$ & 70 & الخبرة الشخصية & \\
\hline YV.AT & rq & الجيزان والأصدقاء & \\
\hline
\end{tabular}

جدول رقم (؛) توزيع المبحوثين من الزراع وفقاً لآرائهم في الزيارات المزرعية والمنزلية.

\begin{tabular}{|c|c|c|c|}
\hline$\%$ & عدد* & \multicolumn{2}{|c|}{ الزيارات الإرشادية } \\
\hline$\& Y . \wedge Y$ & 7. & يقوم بالزيارة & \multirow[t]{2}{*}{ زيارة المرشد } \\
\hline $0 V .1 \leq$ & $\Lambda$. & لا يقوم بالزيارة & \\
\hline V.1E & 1. & دائماً & \multirow{4}{*}{ ت تكرار الزيارة } \\
\hline $1 \leq .49$ & $r$ & أحياناً & \\
\hline$r 1 . \leqslant r$ & $r$ & نادراً & \\
\hline $0 V .1 \leq$ & $\Lambda$. & $y$ & \\
\hline r.ov & 0 & عالية & \multirow[t]{3}{*}{ درجة الإستفادة من الزيارة } \\
\hline ro & ro & متوسطة & \\
\hline $1 \leqslant .4 q$ & $r \cdot$ & منخفضة & \\
\hline
\end{tabular}

جدول رقم (0) توزيع المبحوثين من الزراع وفقاً لآرائهم في الإجتماعات الإششادية

\begin{tabular}{|c|c|c|c|}
\hline$\%$ & ع عدد* & لإجتماعات الإرشادية & \\
\hline$r \wedge .0 \Lambda$ & $\varepsilon$ & سبق له الحضور & \multirow{2}{*}{ حضور الإجتماعات الإرشادية } \\
\hline$V I . \varepsilon r$ & $1 \ldots$ & لم يسبق له الحضور & \\
\hline$r 1 . \leqslant r$ & $r$ & فى الصباح & \multirow{5}{*}{ مو عد إنعقاد الإجتماعات الإرشادية } \\
\hline r.ov & 0 & في الظهر & \\
\hline- & - & فى العصر & \\
\hline r.ov & 0 & في المساء & \\
\hline$V 1 . \leqslant r$ & $1 \ldots$ & لا يعرف & \\
\hline
\end{tabular}

Fayoum J. Agric. Res. \& Dev., Vol.23, No.2, (B) July, 2009 


\begin{tabular}{|c|c|c|c|}
\hline ro.vi & 0. & فى الصباح & \multirow{5}{*}{ أفضل موعد لإنعقاد الإجتماعات الإرشادية } \\
\hline - & - & فى الظهر & \\
\hline ro & ro & فى العصر & \\
\hline ro & ro & في المساء & \\
\hline $1 \leq .49$ & $r \cdot$ & لا يعرف & \\
\hline$r \wedge .0 \wedge$ & $\varepsilon$. & منتظمة & \multirow{2}{*}{ إنتظام الإجتماعات } \\
\hline$V I . \leqslant r$ & $1 \cdots$ & لا يعرف & \\
\hline r.ov & 0 & الملصقات & \multirow{6}{*}{ الإعلان عن الإجتماعات الإرشادية } \\
\hline $1 \leq .49$ & $r \cdot$ & الإتصالات الشخصية & \\
\hline $1 \leq .49$ & $r \cdot$ & أمانة الزر اعة بالبيضاء & \\
\hline r.ov & 0 & إستخدام مكبر ات الصوت & \\
\hline$v .1 \leq$ & $1 \cdot$ & السماع عنها بالصدفة & \\
\hline $0 V .1 \varepsilon$ & $\wedge$. & لا يعرف & \\
\hline Vo & 1.0 & يفضل & \multirow[t]{2}{*}{ تفضيل حضور الإجتماعات الإرشادية } \\
\hline ro & ro & لايفضل & \\
\hline $1 \leq .49$ & $r \cdot$ & أقل من · r مزار عاً & \multirow{4}{*}{ عدد الزراع الحاضرين } \\
\hline$V .1 \leq$ & 1. & 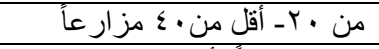 & \\
\hline V.1 $1 \varepsilon$ & 1. & · عمزارعاً فأكثر & \\
\hline$V I \Sigma T$ & $1 \cdots$ & لا يعرف & \\
\hline $1 V . \wedge 7$ & 90 & عدم الإعلان عنه & \multirow{5}{*}{ أسباب عدم حضور الإجتماعات الإرشادية } \\
\hline$\leqslant 1 . \leqslant r$ & 01 & عدم معرفة الزر اع لمكان إنعقاده & \\
\hline $1 \leq .49$ & $r$. & عدم تجاوب الزراع & \\
\hline $1 V . \wedge 7$ & ro & مو عدإنعقاده غير مناسب & \\
\hline V.I & 1. & مكان إنعقاده غير مناسب & \\
\hline
\end{tabular}

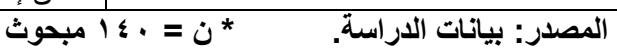

جدول رقم (T) توزيع المبحوثين من الزراع وفقاً لآرائهم في الحقول الإرشادية.

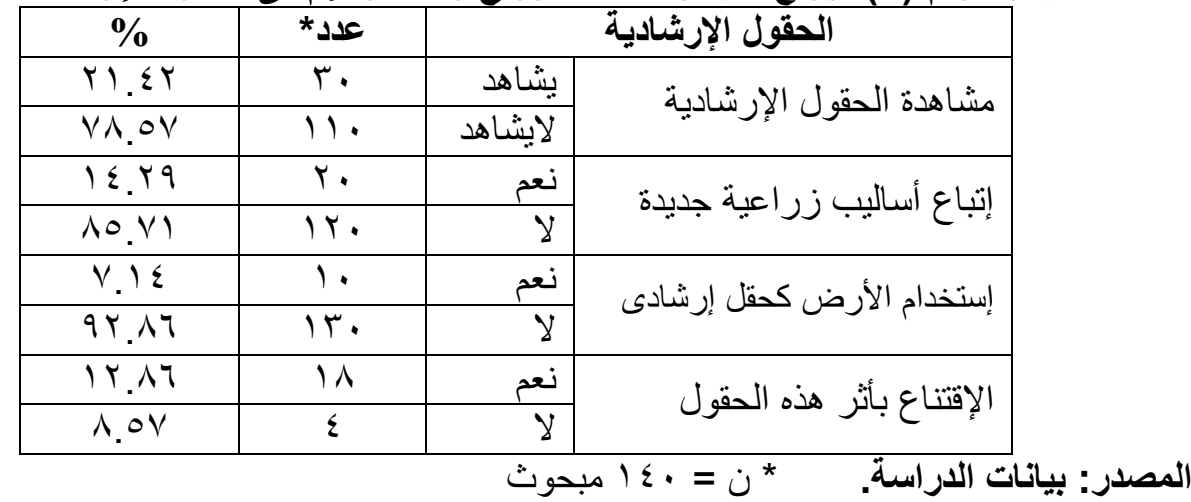

جدول رقم (v ) توزيع المبحوثين من الزراع وفقاً لآرائهم فى المطبوعات الإرشادية ومجالات الإستفادة منها.

\begin{tabular}{|c|c|c|c|c|}
\hline$\%$ & عدد* & & طبوعات الإرشادية & \\
\hline YA.OV & $\varepsilon$ & نعم & الحصول على مطبو عات إرشادية & \\
\hline$V 1 . \leqslant r$ & $1 \ldots$ & $\bar{\gamma}$ & & \\
\hline $1 Y . \wedge 7$ & 11 & | مجلات إرشادية & \multirow{3}{*}{ نو عية المطبو عات الإرشادية } & آر اء الــــــزر اع فـــــى \\
\hline 1 . & $1 \varepsilon$ & نشر ات إرشادية & & المطبو عات الإرشَادية \\
\hline $0 . V 1$ & $\Lambda$ & |ملصقات & & \\
\hline $1 \cdot . \mathrm{VI}$ & 10 & 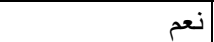 & \multirow[t]{3}{*}{ الإحتفاظ بها } & \\
\hline 19.19 & 140 & $\bar{\gamma}$ & & \\
\hline $1 \cdot . v 1$ & 10 & تحقق كل الأهداف & & \\
\hline
\end{tabular}

Fayoum J. Agric. Res. \& Dev., Vol.23, No.2, (B) July, 2009 
$1+4$

\begin{tabular}{|c|c|c|c|c|}
\hline $1 \leqslant .19$ & $r \cdot$ & تحقق جزء منها & & \\
\hline Vo & 1.0 & لاتحقق أى هدف & & \\
\hline$\sum Y . \wedge T$ & 7. & & معرفة أصناف جديدة & \multirow{6}{*}{ 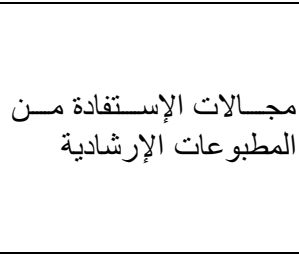 } \\
\hline $0 V .1 \varepsilon$ & A. & & التعرف على طرق مقاومة و علاج الأمر اض & \\
\hline TY.Is & $\leqslant 0$ & & تغذية ورعاية الماشية & \\
\hline $1 \leqslant . Y \Lambda$ & $r \cdot$ & & معرفة سلالات جديدة من الماشية و الدو اجن & \\
\hline ro.VI & 0. & & معرفة طرق ونظم الرى المناسبة & \\
\hline $7 \cdot .11$ & 10 & & معرفة طرق التسميد & \\
\hline
\end{tabular}

جدول رقم (^) قيم معامـل الإرتبـاط بين درجـة إستجابة الزراع للطرق الإرشـادية وكل مـن

المتفيرات المستقلة المدروسة المعادية

\begin{tabular}{|c|c|}
\hline قيمة معامل الإرتباط & متغيرات الدراسة \\
\hline$* * \cdot . \mathrm{TV}$ & العمر العر \\
\hline$-\cdot \cdot{ }^{r}$ & الحالة التعليمية \\
\hline$-\cdot .117$ & المهنة \\
\hline$-\because .19$ & حجم الحيازة \\
\hline$-\cdot . Y q$ & عضوية المنظمات \\
\hline$-\cdot Y \wedge \wedge$ & ملكية الحيوانات المزرعية \\
\hline$-\cdot .1 \wedge \mathrm{V}$ & ملكية المشروعات الزراعية والإنتاجية \\
\hline
\end{tabular}

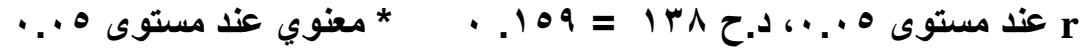

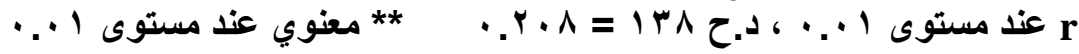

\title{
A STUDY OF FARMERS RESPONSE LIMITATIONS USING AGENTS TO EXTENSION METHODS IN THE GREEN MOUNTAIN AREA OF LIBYA
}

\section{Abdel-Shafy, A. Azam and Mohamed E. Ferkash}

\begin{abstract}
The main objective of this study was determining the factors which are affecting the response of farmers to agricultural extension methods. The study was aimed-also-to: (a) determine farmers opinion in extension methods, and their confidence in these methods, and (b) determine the relationship between some personal characteristics of respondents and there response to extension methods.

A random sample of 140 respondents was chosien from four destercts in the Green Mountain. Percentages, means, varience, and simple correlation coefficient were used to analyses the data.

The results showed that:

(a) The majority of respondents are less than 56 years old, illetrate, working in farming, holding not more than 3 hektars, members in social organizations, and have not agricultural projects.

(b) The response to extension methods was between $2.14 \%$ (personal letters), and $28.57 \%$ (extension meetings

(c) The majority of respondents meintioned that:
\end{abstract}

Fayoum J. Agric. Res. \& Dev., Vol.23, No.2, (B) July, 2009 
*Their confidence in extension methods was at middle degree, and they prefer whom have expertness as information resource.

*Extension workers don't perform any farm or home visits. And there is no benefit to this method

*They haven't attend extension meetings because they don't know the date and place of meeting

*They never saw extension fields, and therefore they haven't feeling with these fields effect.

* They never received any extension publications, in spite of, they expect that they can get information about fertilization, and deseise from extension publications

(d) A positive relationship was found between the degree of response to extension methods and respondents age, while a negative relationship was found with the agricultural projects, and the Animal. 